\title{
Comparison of the Finite Volume and Lattice Boltzmann Methods for Solving Natural Convection Heat Transfer Problems inside Cavities and Enclosures
}

\author{
M. Goodarzi, ${ }^{1}$ M. R. Safaei, ${ }^{2}$ A. Karimipour, ${ }^{3}$ K. Hooman, ${ }^{4}$ M. Dahari, ${ }^{2}$ \\ S. N. Kazi, ${ }^{2}$ and E. Sadeghinezhad ${ }^{2}$ \\ ${ }^{1}$ Department of Software Engineering, Faculty of Computer Science \& Information Technology, University of Malaya, \\ 50603 Kuala Lumpur, Malaysia \\ ${ }^{2}$ Department of Mechanical Engineering, Faculty of Engineering, University of Malaya, 50603 Kuala Lumpur, Malaysia \\ ${ }^{3}$ Department of Mechanical Engineering, Najafabad Branch, Islamic Azad University, Isfahan, Iran \\ ${ }^{4}$ School of Mechanical and Mining Engineering, The University of Queensland, St Lucia, Brisbane, QLD 4072, Australia \\ Correspondence should be addressed to M. R. Safaei; cfd_safaei@yahoo.com
}

Received 28 September 2013; Revised 22 November 2013; Accepted 24 November 2013; Published 9 February 2014

Academic Editor: Mohamed Fathy El-Amin

Copyright @ 2014 M. Goodarzi et al. This is an open access article distributed under the Creative Commons Attribution License, which permits unrestricted use, distribution, and reproduction in any medium, provided the original work is properly cited.

\begin{abstract}
Different numerical methods have been implemented to simulate internal natural convection heat transfer and also to identify the most accurate and efficient one. A laterally heated square enclosure, filled with air, was studied. A FORTRAN code based on the lattice Boltzmann method (LBM) was developed for this purpose. The finite difference method was applied to discretize the LBM equations. Furthermore, for comparison purpose, the commercially available CFD package FLUENT, which uses finite volume Method (FVM), was also used to simulate the same problem. Different discretization schemes, being the first order upwind, second order upwind, power law, and QUICK, were used with the finite volume solver where the SIMPLE and SIMPLEC algorithms linked the velocity-pressure terms. The results were also compared with existing experimental and numerical data. It was observed that the finite volume method requires less CPU usage time and yields more accurate results compared to the LBM. It has been noted that the 1st order upwind/SIMPLEC combination converges comparatively quickly with a very high accuracy especially at the boundaries. Interestingly, all variants of FVM discretization/pressure-velocity linking methods lead to almost the same number of iterations to converge but higher-order schemes ask for longer iterations.
\end{abstract}

\section{Introduction}

Studying heat transfer and fluid flow using computational methods is easier [1], safer [2], and much less costly [3] compared to experimental techniques. There are a large number of problems which can be simulated with great accuracy to replicate experiments with high resolutions [4]. There are currently a range of approaches with the potential to serve in modeling heat transfer and fluid flows, such as the finite difference method (FDM), finite element method (FEM), finite volume method (FVM), lattice boltzmann method (LBM), boundary elements method (BEM), molecular dynamics simulation, and direct simulation Monte Carlo. The most widely employed approaches in the field of thermofluids are the first four [5]. However, application of FDM can be difficult when complex geometries are involved [6]. The FEM schemes can be intricate for solving conservative equations, while the nonstandard FEMs have low computational efficiency [7]. Application of FVM is difficult and complex to cases with complex moving boundaries [8]. LBM is a compressible model for ideal gases and can theoretically always simulate the compressible Navier-Stokes equations. With the Chapman-Enskog expansion [9], LBM can simulate incompressible flow for low Mach numbers $(\mathrm{Ma}<0.15)$ albeit at the expense of a compressibility error [10, 11]. Besides, regular square grids used with LBM make it very hard to extend the simulation to curved boundaries [12]. All in all, the accuracy of all these numerical approaches is dependent 


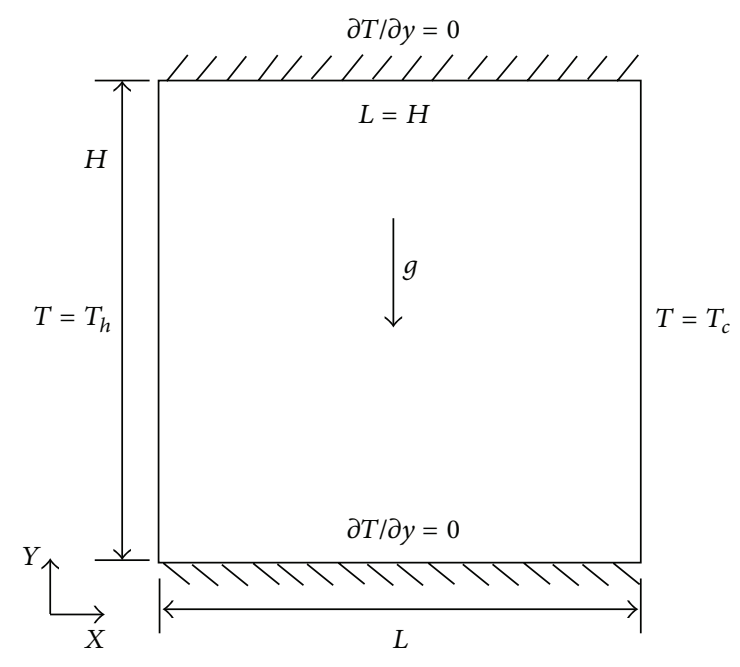

FIGURE 1: Schematic of analyzed configuration.

on the problem configuration, discretization scheme, and numerical algorithm used [5]. As such, an important question to answer is about finding the best approach to solve a certain problem subject to computational efficiency and accuracy as the most important constrains. Along these lines, Rouboa and Monteiro [13] investigated the heat transfer phenomenon during cast solidification in a complicated configuration by FVM and FDM. A comparison between the numerical results and experimental ones indicated that both discretization approaches produced good outcome, with FVM being slightly better as it uses more information than FDM to capture spatial temperature variations. Despite recent progress in computing power and techniques, the literature review indicates a lack of comprehensive studies on selecting the ideal means of analyzing internal heat transfer and fluid flow problems. In particular, an optimal solution technique and procedure to simulate internal natural convection are yet to be presented. To fill this gap in the literature, laminar natural convection heat transfer of air inside a laterally heated square enclosure is investigated using both FVM and LBM. The simulation results were compared against those from the literature. Particular attention was given to different discretization techniques as well as pressure-velocity linking approaches to find the best method for simulating internal free convection problems.

\section{Governing Equations}

2.1. Finite Volume Method. Continuity, momentum, and energy equations were employed for flow analysis in a system depicted by Figure 1. Density was computed by invoking the Boussinesq approximation for $\Delta T<30^{\circ} \mathrm{C}$ [14]. The governing equations are written as follows [15].

Continuity equation:

$$
\frac{\partial u}{\partial x}+\frac{\partial v}{\partial y}=0
$$

Momentum equations in $X$ and $Y$ directions:

$$
\begin{gathered}
u \frac{\partial u}{\partial x}+v \frac{\partial u}{\partial y}=\frac{-1}{\rho} \frac{\partial p}{\partial x}+\frac{\mu}{\rho}\left(\frac{\partial^{2} u}{\partial x^{2}}+\frac{\partial^{2} u}{\partial y^{2}}\right) \\
u \frac{\partial v}{\partial x}+v \frac{\partial v}{\partial y}=\frac{-1}{\rho} \frac{\partial p}{\partial y}+\frac{\mu}{\rho}\left(\frac{\partial^{2} v}{\partial x^{2}}+\frac{\partial^{2} v}{\partial y^{2}}\right)+\beta g\left(T-T_{c}\right) .
\end{gathered}
$$

Energy equation:

$$
u \frac{\partial T}{\partial x}+v \frac{\partial T}{\partial y}=\frac{k}{\rho C_{p}}\left(\frac{\partial^{2} T}{\partial x^{2}}+\frac{\partial^{2} T}{\partial y^{2}}\right)
$$

2.2. Lattice Boltzmann Method. The hydrodynamic and thermal Boltzmann equations with using density-momentum and internal energy distribution functions (double population) are as follows $[16,17]$ :

$$
\begin{gathered}
\frac{\partial f_{i}}{\partial t}+c_{i \alpha} \frac{\partial f_{i}}{\partial x_{\alpha}}=\Omega(f)=-\frac{1}{\tau_{f}}\left(f_{i}-f_{i}^{e}\right) \\
\frac{\partial g_{i}}{\partial t}+c_{i \alpha} \frac{\partial g_{i}}{\partial x_{\alpha}}=\Omega\left(g_{i}\right)-f_{i} Z_{i}=0.5|\mathbf{c}-\mathbf{u}|^{2} \Omega\left(f_{i}\right)-f_{i} Z_{i} \\
=-\frac{g_{i}-g_{i}^{e}}{\tau_{g}}-f_{i} Z_{i} .
\end{gathered}
$$

Double population LBM model (TLBM) uses two separated distribution functions $f$ and $g$ for hydrodynamic and thermal fields, respectively. This model is the latest one among different presented models of thermal LBMs. In addition, it shows more accuracy and stability during the solution process. As LBM solution process naturally tends to divergence having a stable approach like TLBM helps the convergence. Microscopic velocities for a D2Q9 lattice model are [12]

$$
\begin{gathered}
\mathbf{c}_{i}=\left(\cos \frac{i-1}{2} \pi, \sin \frac{i-1}{2} \pi\right), \quad i=1,2,3,4, \\
\mathbf{c}_{i}=\sqrt{2}\left(\cos \left[\frac{(i-5)}{2} \pi+\frac{\pi}{4}\right], \sin \left[\frac{(i-5)}{2} \pi+\frac{\pi}{4}\right]\right), \\
i=5,6,7,8, \\
\mathbf{c}_{0}=(0,0) .
\end{gathered}
$$

Heat dissipation and hydrodynamic and thermal equilibrium distribution functions are given by

$$
\begin{gathered}
Z_{i}=\left(c_{i \alpha}-u_{\alpha}\right)\left[\frac{\delta u_{\alpha}}{\delta t}+c_{i \alpha} \frac{\partial u_{\alpha}}{\partial x_{\alpha}}\right], \\
f_{i}^{e}=\omega_{i} \rho\left[1+3\left(\mathbf{c}_{i} \cdot \mathbf{u}\right)+\frac{9\left(\mathbf{c}_{i} \cdot \mathbf{u}\right)^{2}}{2}-\frac{3 \mathbf{u}^{2}}{2}\right], \\
i=0,1, \ldots, 8, \\
\omega_{0}=\frac{4}{9}, \quad \omega_{1,2,3,4}=\frac{1}{9}, \quad \omega_{5,6,7,8}=\frac{1}{36}
\end{gathered}
$$




$$
\begin{gathered}
g_{0}^{e}=-\frac{2}{3} \rho e \mathbf{u}^{2}, \\
g_{1,2,3,4}^{e}=\frac{1}{9} \rho e\left[1.5+1.5\left(\mathbf{c}_{1,2,3,4} \cdot \mathbf{u}\right)\right. \\
\left.+4.5\left(\mathbf{c}_{1,2,3,4} \cdot \mathbf{u}\right)^{2}-1.5 \mathbf{u}^{2}\right], \\
g_{5,6,7,8}^{e}=\frac{1}{36} \rho e\left[3+6\left(\mathbf{c}_{5,6,7,8} \cdot \mathbf{u}\right)\right. \\
\left.+4.5\left(\mathbf{c}_{5,6,7,8} \cdot \mathbf{u}\right)^{2}-1.5 \mathbf{u}^{2}\right],
\end{gathered}
$$

where $\rho e=\rho R T$ and $\omega$ is the weight function. Equation (4) in discretized forms [18] reads

$$
\begin{aligned}
f_{i}(\mathbf{x}+ & \left.\mathbf{c}_{i} \Delta t, t+\Delta t\right)-f_{i}(\mathbf{x}, t) \\
= & -\frac{\Delta t}{2 \tau_{f}}\left[f_{i}\left(\mathbf{x}+\mathbf{c}_{i} \Delta t, t+\Delta t\right)-f_{i}^{e}\left(\mathbf{x}+\mathbf{c}_{i} \Delta t, t+\Delta t\right)\right] \\
& -\frac{\Delta t}{2 \tau_{f}}\left[f_{i}(\mathbf{x}, t)-f_{i}^{e}(\mathbf{x}, t)\right], \\
g_{i}(\mathbf{x}+ & \left.\mathbf{c}_{i} \Delta t, t+\Delta t\right)-g_{i}(\mathbf{x}, t) \\
= & -\frac{\Delta t}{2 \tau_{g}}\left[g_{i}\left(\mathbf{x}+\mathbf{c}_{i} \Delta t, t+\Delta t\right)-g_{i}^{e}\left(\mathbf{x}+\mathbf{c}_{i} \Delta t, t+\Delta t\right)\right] \\
& -\frac{\Delta t}{2} f_{i}\left(\mathbf{x}+\mathbf{c}_{i} \Delta t, t+\Delta t\right) Z_{i}\left(\mathbf{x}+\mathbf{c}_{i} \Delta t, t+\Delta t\right) \\
& -\frac{\Delta t}{2 \tau_{g}}\left[g_{i}(\mathbf{x}, t)-g_{i}^{e}(\mathbf{x}, t)\right]-\frac{\Delta t}{2} f_{i}(\mathbf{x}, t) Z_{i}(\mathbf{x}, t) .
\end{aligned}
$$

The two last equations are implicit. Thus, the new functions $\tilde{f}_{i}$ and $\tilde{g}_{i}$ are developed to address this problem:

$$
\begin{gathered}
\tilde{f}_{i}=f_{i}+\frac{\Delta t}{2 \tau_{f}}\left(f_{i}-f_{i}^{e}\right), \\
\tilde{g}_{i}=g_{i}+\frac{\Delta t}{2 \tau_{g}}\left(g_{i}-g_{i}^{e}\right)+\frac{\Delta t}{2} f_{i} Z_{i} .
\end{gathered}
$$

Collision and streaming steps of LBM are simulated by applying (7)-(9) as follows:

$$
\begin{aligned}
\tilde{f}_{i}(\mathbf{x} & \left.+\mathbf{c}_{i} \Delta t, t+\Delta t\right)-\tilde{f}_{i}(\mathbf{x}, t) \\
& =-\frac{\Delta t}{\tau_{f}+0.5 \Delta t}\left[\tilde{f}_{i}(\mathbf{x}, t)-f_{i}^{e}(\mathbf{x}, t)\right] \\
\tilde{g}_{i}(\mathbf{x} & \left.+\mathbf{c}_{i} \Delta t, t+\Delta t\right)-\tilde{g}_{i}(\mathbf{x}, t) \\
& =-\frac{\Delta t}{\tau_{g}+0.5 \Delta t}\left[\tilde{g}_{i}(\mathbf{x}, t)-g_{i}^{e}(\mathbf{x}, t)\right]-\frac{\tau_{g} \Delta t}{\tau_{g}+0.5 \Delta t} f_{i} Z_{i} .
\end{aligned}
$$

Finally, the hydrodynamic and thermal variables can be obtained as

$$
\begin{gathered}
\rho=\sum_{i} \widetilde{f}_{i}, \\
\rho \mathbf{u}=\sum_{i} \mathbf{c}_{i} \widetilde{f}_{i}, \\
\rho e=\rho R T=\sum_{i} \widetilde{g}_{i}-\frac{\Delta t}{2} \sum_{i} f_{i} Z_{i} .
\end{gathered}
$$

\section{Boundary Conditions}

Figure 1 illustrates a schematic of the configuration analyzed in the present study along with the boundary conditions.

The nonequilibrium bounce-back model is used to simulate the no-slip boundary condition on the walls in LBM. This model improves accuracy compared to the usual bounceback boundary condition and satisfies the zero mass flow rates at nodes on the wall. The collision occurs on the nodes located at the solid-fluid boundaries and distribution functions are reflected in a suitable direction, satisfying the equilibrium conditions [19].

The macroscopic boundary conditions for the present study are

$$
\begin{array}{llll}
T=T_{h} & u=v=0 & 0<y<1 & x=0, \\
T=T_{c} & u=v=0 & 0<y<1 & x=1, \\
\frac{\partial T}{\partial y}=0 & u=v=0 & 0<x<1 & y=0, \\
\frac{\partial T}{\partial y}=0 & u=v=0 & 0<x<1 & y=1 .
\end{array}
$$

\section{Numerical Procedure}

Our FVM solver uses the implicit line-by-line tridiagonal matrix algorithm $[20,21]$ to linearize the system of algebraic equations. First order upwind [22], second order upwind [23], power law [24], and Quadratic Upstream Interpolation for Convective Kinetics (QUICK) [25] schemes were applied in different trails to solve the same problem while the Semi-Implicit Method for Pressure-Linked Equations (SIMPLE) $[26,27]$ and SIMPLE-Consistent (SIMPLEC) [28, 29] procedures were selected for pressure-velocity coupling. The convergence criterion, maximum absolute error in each dependent variable, was set at $10^{-7}$.

In LBM, the zero values for $U(x, y), V(x, y)$, and $T(x, y)$ are applied as the initial conditions. However, to avoid problems in estimating the macroscopic variables in (12), the initial fluid density is set to unity. LBM dimensionless numbers $\mathrm{Re}, \mathrm{Ra}$, and $\mathrm{Pr}$ are defined identical to those of classical Navier-Stokes equations. However, the macroscopic numerical value should be calculated beforehand. For example, for $\operatorname{Pr}$, one has the kinematics viscosity and thermal diffusivity determined in LBM as $\nu=\tau_{f} R T$ and $\alpha=2 \tau_{g} R T$, where $\tau_{f}$ and $\tau_{g}$ are hydrodynamic and thermal relaxation times and $R$ is the gas constant. The Prandtl number can 
then be written as $\operatorname{Pr}=v / \alpha=\tau_{f} R T / 2 \tau_{g} R T=\tau_{f} / 2 \tau_{g}$. For $\mathrm{Ra}=\mathrm{GrPr}=g \beta \Delta T H^{3} / v \alpha$ the values of $v$ and $\alpha$ are now known based on relaxation times, while the numerical values of $g, \beta, H, \Delta T$ are predetermined and fixed.

4.1. Gravity Effects in $L B M$. The Boussinesq approximation was used as $\rho=\bar{\rho}[1-\beta(T-\bar{T})]$ to give buoyancy force per unit mass defined as $\mathbf{G}=\beta \mathbf{g}(T-\bar{T})$ and $f=G \cdot(c-u) f^{e} / R T$. Hence, the discretized Boltzmann equation is written as

$$
\begin{gathered}
\partial_{t} f_{i}+\left(\mathbf{c}_{i} \cdot \nabla\right) f_{i}=-\frac{f_{i}-f_{i}^{e}}{\tau_{f}}+\frac{\mathbf{G} \cdot\left(\mathbf{c}_{i}-\mathbf{u}\right)}{R T} f_{i}^{e}, \\
\tilde{f}_{i}\left(\mathbf{x}+\mathbf{c}_{i} \Delta t, t+\Delta t\right)-\tilde{f}_{i}(\mathbf{x}, t) \\
=-\frac{\Delta t}{\tau_{f}+0.5 \Delta t}\left[\tilde{f}_{i}-f_{i}^{e}\right]+\frac{\Delta t \tau_{f}}{\tau_{f}+0.5 \Delta t} \frac{3 G\left(c_{i y}-v\right)}{c^{2}} f_{i}^{e} .
\end{gathered}
$$

Applying (8) and taking into consideration the effects of gravity, one has

$$
\begin{gathered}
\rho=\sum_{i} \widetilde{f}_{i}, \quad u=\left(\frac{1}{\rho}\right) \sum_{i} \widetilde{f}_{i} c_{i x}, \\
v=\left(\frac{1}{\rho}\right) \sum_{i} \widetilde{f}_{i} c_{i y}+\frac{\Delta t}{2} G,
\end{gathered}
$$

while for thermal macroscopic variables (11) is applied.

4.2. Deriving Navier-Stokes Equations from LBM. In order to derive Navier-Stokes equations from the incompressible lattice Boltzmann equation by using Chapman-Enskog expansion the discretized form of Boltzmann equation can be written as

$$
f_{i}\left(\mathbf{x}+\mathbf{c}_{i} \Delta t, t+\Delta t\right)-f_{i}(\mathbf{x}, t)=-\frac{f_{i}(\mathbf{x}, t)-f_{i}^{e}(\mathbf{x}, t)}{\tau_{f}} .
$$

With $K n=\varepsilon$ as a small (perturbation) variable, the Chapman-Enskog expansion for $f_{\alpha}$ and $\partial_{t}$ reads

$$
\begin{gathered}
f_{i}=\sum_{n=0}^{\infty} \varepsilon^{n} f_{i}^{(n)}=f_{i}^{(0)}+\left[\varepsilon f_{i}^{(1)}+\varepsilon^{2} f_{i}^{(2)}+\cdots\right] \\
=f_{i}^{(\mathrm{eq})}+\left[f_{i}^{(n e \mathrm{q})}\right] \\
\partial_{t}=\sum_{n=0}^{\infty} \varepsilon^{n} \partial_{t_{n}}=\partial_{t_{0}}+\varepsilon \partial_{t_{1}}+\cdots .
\end{gathered}
$$

None of the nonequilibrium parts of the above equations should be used for estimating the macroscopic properties $\rho$ and $\rho \mathbf{u}$ :

$$
\begin{gathered}
\sum_{i} \varepsilon^{n} f_{i}^{(n)}=0 \quad \forall n>0, \\
\sum_{i} \mathbf{c}_{i} \varepsilon^{n} f_{i}^{(n)}=0 \quad \forall n>0 .
\end{gathered}
$$

Using these equations together with Tailor expansion of Boltzmann equation around $\Delta t$, the terms which are smaller than $(\Delta t)$ dropped, and then substitute into (15), we have

$$
\begin{gathered}
{\left[\partial_{t_{0}}+\mathbf{c}_{i} \cdot \nabla\right] f_{i}^{(0)}=-\frac{f_{i}^{(1)}}{\tau_{f}},} \\
\partial_{t_{1}} f_{i}^{(0)}+\left(1-\frac{1}{2 \tau_{f}}\right)\left[\partial_{t_{0}}+\mathbf{c}_{i} \cdot \nabla\right] f_{i}^{(1)}=-\frac{f_{i}^{(2)}}{\tau_{f}} .
\end{gathered}
$$

Macroscopic density and velocity variables can be achieved by applying the first and second order of moments, leading to

$$
\begin{gathered}
\partial_{t} \sum_{i} f_{i}^{(0)}+\nabla \cdot\left(\sum_{i} \mathbf{c}_{i} f_{i}^{(0)}\right)=0, \\
\partial_{t}\left(\sum_{i} \mathbf{c}_{i} f_{i}^{(0)}\right)+\nabla \cdot\left[\Pi^{(0)}+\Delta t\left(1-\frac{1}{2 \tau_{f}}\right) \Pi^{(1)}\right]=O\left(\Delta t^{2}\right),
\end{gathered}
$$

where

$$
\begin{aligned}
& \Pi^{(0)} \equiv \sum_{i} \mathbf{c}_{i} \mathbf{c}_{i} f_{i}^{(0)}, \\
& \Pi^{(1)} \equiv \sum_{i} \mathbf{c}_{i} \mathbf{c}_{i} f_{i}^{(1)} .
\end{aligned}
$$

Amount of $f_{i}^{(0)}$ is determined by using $f_{i}^{e}=\omega_{i} \rho\left[1+3\left(\mathbf{c}_{i} \cdot \mathbf{u}\right)+\right.$ $\left.\left(9\left(\mathbf{c}_{i} \cdot \mathbf{u}\right)^{2} / 2\right)-\left(3 \mathbf{u}^{2} / 2\right)\right]$ and then using the zero and first order of moments of (18) together with $f_{i}^{(0)}$ :

$$
\begin{gathered}
\partial_{t_{0}} \rho+\nabla \cdot(\rho \mathbf{u})=0, \\
\partial_{t_{1}} \rho=0, \\
\partial_{t_{0}}(\rho \mathbf{u})+\nabla \cdot(\rho \mathbf{u u})+\nabla\left(\rho c_{s}^{2}\right)=0, \\
\partial_{t_{1}} \rho+\nabla \cdot\left(2 v \rho S-\Delta t\left(\tau_{f}-0.5\right) \nabla \cdot(\rho \mathbf{u u u})\right)=0,
\end{gathered}
$$

where

$$
\begin{aligned}
& S=\frac{\nabla \mathbf{u}+(\nabla \mathbf{u})^{T}}{2}, \\
& v=\frac{\left(2 \tau_{f}-1\right) \Delta t}{6} .
\end{aligned}
$$

Finally, making use of $\nabla \cdot \mathbf{u}=0, \nabla \rho=0$ at incompressible limit and ignoring the term $\nabla \cdot(\rho \mathbf{u u u})$ in (21), continuity and momentum equations are recovered. In addition, the thermal energy equation would be recovered in a similar way; see [30, 31] for more details.

\section{Grid Independence}

Structured nonuniform grid distributions were applied for FVM simulations with a grid cluster near the walls to capture sharp velocity and temperature gradients. For LBM simulations structured grids based on D2Q9 lattice are applied. 
TABLE 1: Grid independence tests (FVM and QUICK/SIMPLEC).

\begin{tabular}{lccccc}
\hline Number of grids & 15987 & 31974 & 47961 & 63948 & Experimental value [32] \\
\hline Maximum $X$-velocity & 0.001 & 0.001 & 0.0012 & 0.0012 & - \\
Dimensionless temperature at the middle of the cavity & 0.460 & 0.465 & 0.489 & 0.493 & 0.51 \\
\hline
\end{tabular}

TABLE 2: Grid independence tests (LBM).

\begin{tabular}{lccccccc}
\hline Number of grids & 10000 & 32400 & 48400 & 67600 & 84100 & Experimental value [32] \\
\hline Maximum $X$-velocity & 0.0004 & 0.0008 & 0.0010 & 0.0010 & 0.00103 & - \\
Dimensionless temperature at the middle of the cavity & 0.430 & 0.449 & 0.463 & 0.471 & 0.475 & 0.51 \\
\hline
\end{tabular}

TABLE 3: Thermophysical properties of air [33].

\begin{tabular}{cccccccc}
\hline$\rho$ & $C_{p}$ & $\mu$ & $k$ & Gr & $\operatorname{Pr}$ & $\mathrm{Ra}$ \\
\hline 1.127 & 1007 & $1.9114 \times 10^{-5}$ & 0.0271 & 0.006092 & $2.662 \times 10^{5}$ & 0.71 & $1.890 \times 10^{5}$ \\
\hline
\end{tabular}

Extensive grid independence checks were performed, as indicated by Tables 1 and 2, to observe that a grid with 47961 and 67600 cells for all FVM solvers and LBM, respectively, leads to mesh-independent results.

\section{Results}

Our numerical results, from different solvers, were compared with benchmark experimental data from Krane and Jessee [32] as well as the numerical predictions of Khanafer et al. [34], Oztop and Abu-Nada [35], and Bakhshan and Emrani [33]. The main dimensionless parameters were the Rayleigh and Prandtl numbers, which are constant at $1.89 \times 10^{5}$ and 0.71 , respectively. The fluid thermophysical properties, as well as dimensionless numbers, are shown in Table 3.

For $\operatorname{Pr}=0.71$ and $\mathrm{Ra}=1.89 \times 10^{5}$, the dimensionless temperature and vertical velocity profiles at midheight are plotted in Figures 2 and 3 and contrasted with the results from [32-35]. These figures illustrate a superior adaptation between the present simulation results using the FVM and LBM models and those of [32-35] works. Although previous research shows that, for complicated turbulent fluid flow problems, the QUICK/SIMPLEC is the most accurate choice [33], Figures 2(a) and 3(a) indicate that for laminar internal convection heat transfer problems there is no dramatic difference among the studied discretization approaches. However, it is obvious from Figures 2 and 3 that the FVM results are more accurate than those of LBM. This could be attributed to the compressible nature of LBM $[36,37]$, which creates a compressibility error for incompressible flows [12]. Among the discretization/pressure-velocity linking approaches examined, 1st order upwind/SIMPLEC has the closest results to experimental benchmark data, especially for the temperature contours in the range $0.20 \leq X \leq 0.80$. With vertical velocity distribution, however, the difference among FVM approaches is quite negligible. Nevertheless, the fact that the accuracy and stability of the convective terms comprise a contrasting pair is a general perception in the field of computational heat transfer. For instance, the first order upwind scheme is entirely stable even with strong false diffusion [38], while the second or third order schemes like QUICK are conditionally stable [25].

Table 4 successfully compares our numerical results with those available in the literature under similar conditions and geometry over a range of $\mathrm{Ra}$ values with $\operatorname{Pr}=0.7$. Slight discrepancies are observed in this table between some of the present work results and those of [34, 39-42] because of the differences between the employed discretization methods, as well as mesh generation types, as one would expect.

Table 5 provides the comparison of number of iterations and required CPU usage time for the different discretization methods considered here. As seen, LBM may take 4-5 times longer to converge and 8-9 times more iterations compared to FVM. There are two reasons for this. The first one is attributed to the way LBM handles heat transfer. Although in the present work the appropriate internal energy distribution function, $g$, [43] was used to obtain the temperature field, this model even tends to diverge. Furthermore, with LBM modeling the corners ask for a large number of fine grids near the corners. These two matters cause the LBM solutions to be comparatively more time consuming.

According to Table 5, the number of iterations for all FVM discretization method/pressure-velocity linking approaches is nearly equal. In this case, the difference between the QUICK/SIMPLEC method that necessitates the largest number of iterations and the lowest one (power law/SIMPLE) is only 79 iterations, that is, a $5.2 \%$ difference. With respect to CPU usage time, these proportions are to some extent different. For example, when comparing the most time consuming method (QUICK/SIMPLEC) with the 1st order upwind/SIMPLEC approach, this time disparity is about $4.94 \%$, while the number of iterations differs by only $1.65 \%$. As expected, higher-order accurate schemes are more time consuming.

The effects of the solution method, discretization scheme, and pressure/velocity coupling approach on the streamlines and $X$-velocity are illustrated by Figures 4 and 5 . Two elliptical vortexes generally appear at the center of the cavity as a predominant feature of buoyancy-induced flow in a laterally heated square enclosure. In this context, the 1st order upwind scheme has the most precise results among 


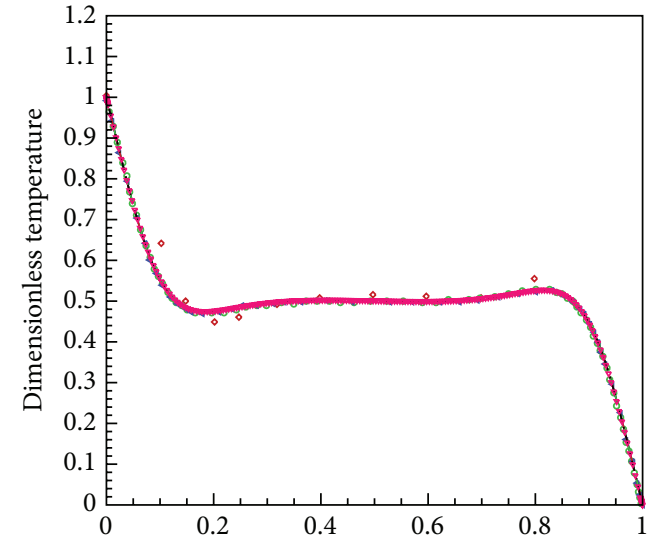

(a) $0.000 \leq X \leq 1.000$

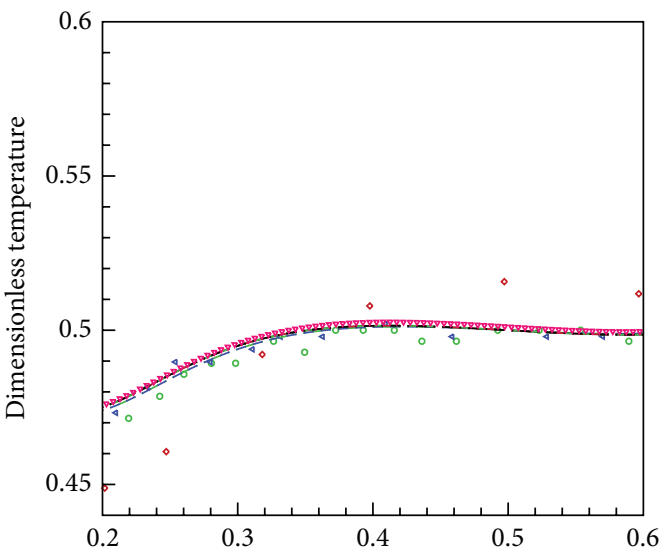

(c) $0.20 \leq X \leq 0.60$

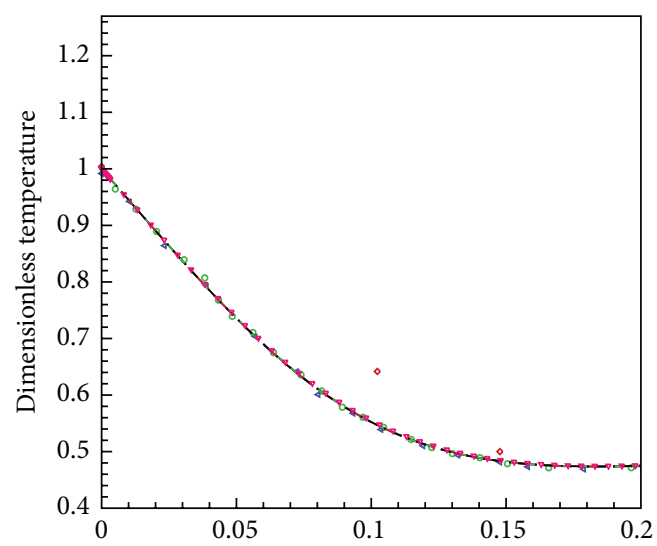

(b) $0.0 \leq X \leq 0.20$

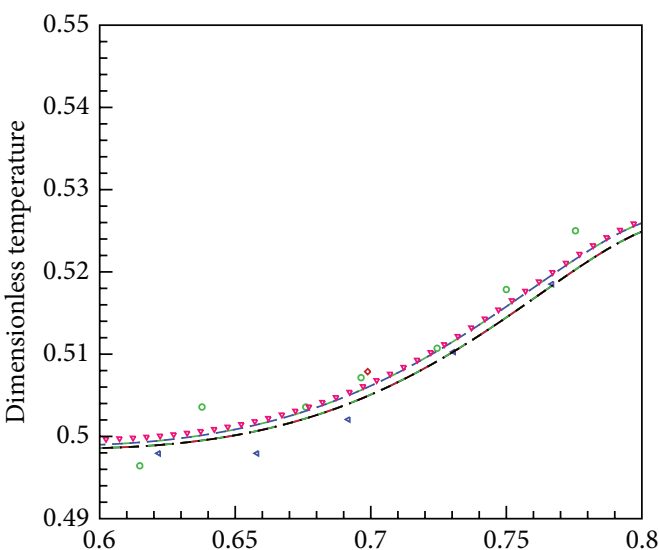

(d) $0.60 \leq X \leq 0.80$

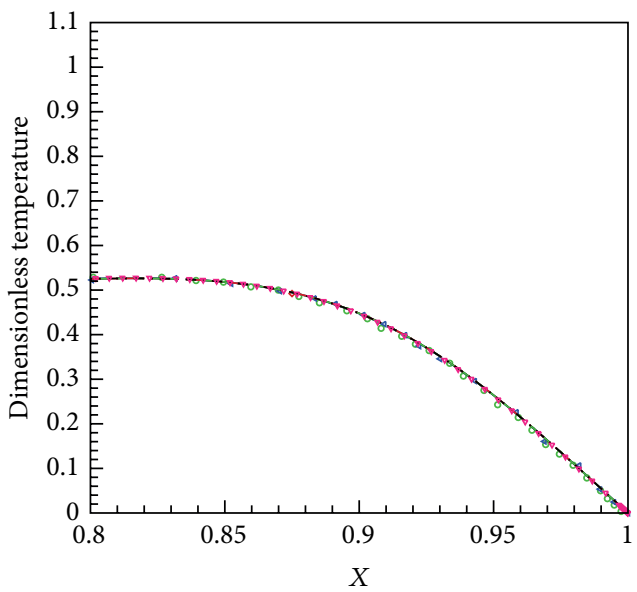

- Krane and Jessee [32], experimental work

- Khanafer et al. [34], numerical work

- Oztop and Abu-Nada [35], numerical work

..... 1st order upwind/SIMPLE

- - - 1st order upwind/SIMPLEC
.... 2nd order upwind/SIMPLE

- - - 2nd order upwind/SIMPLEC

...... Power law/SIMPLE

- . - Power law/SIMPLEC

...... QUICK/SIMPLE

-.. QUICK/SIMPLEC

- LBM

(e) $0.80 \leq X \leq 1.00$

FIGURE 2: Dimensionless temperature representation at midheight. 


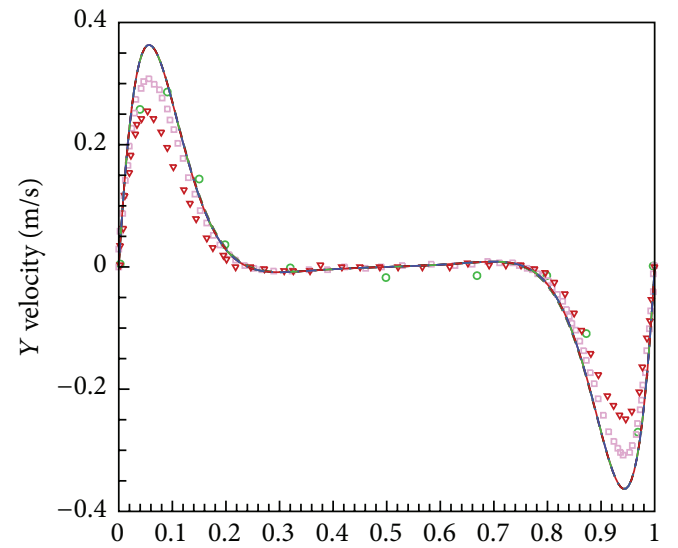

(a) $0.00 \leq X \leq 1.00$

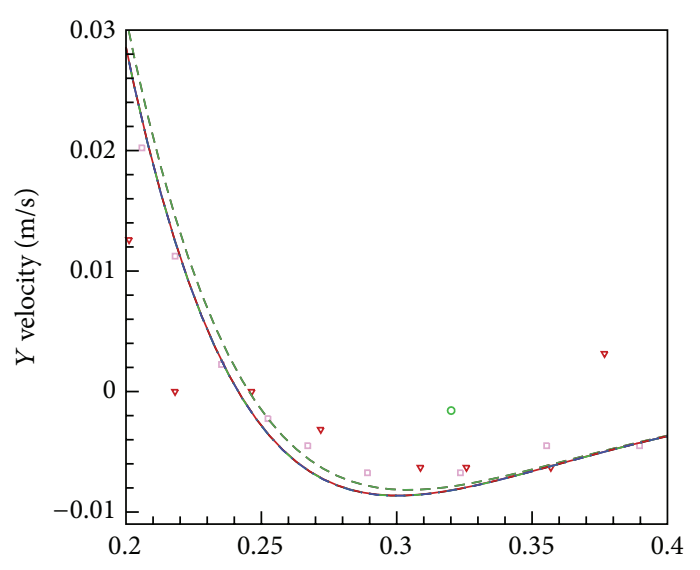

(c) $0.20 \leq X \leq 0.4$

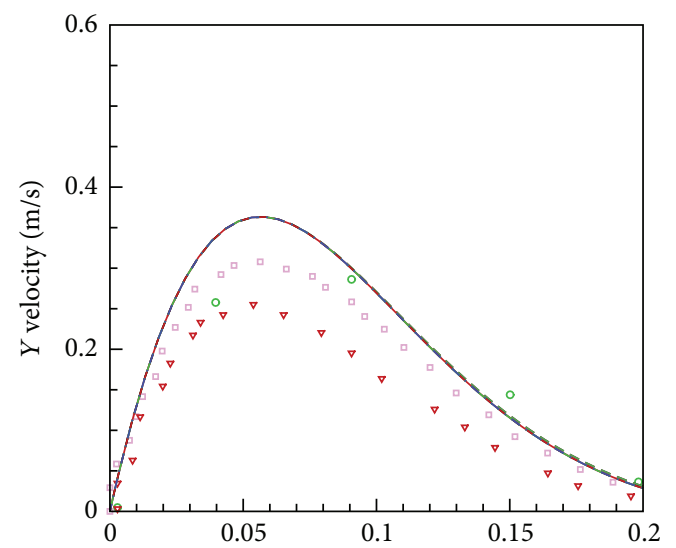

(b) $0.00 \leq X \leq 0.20$

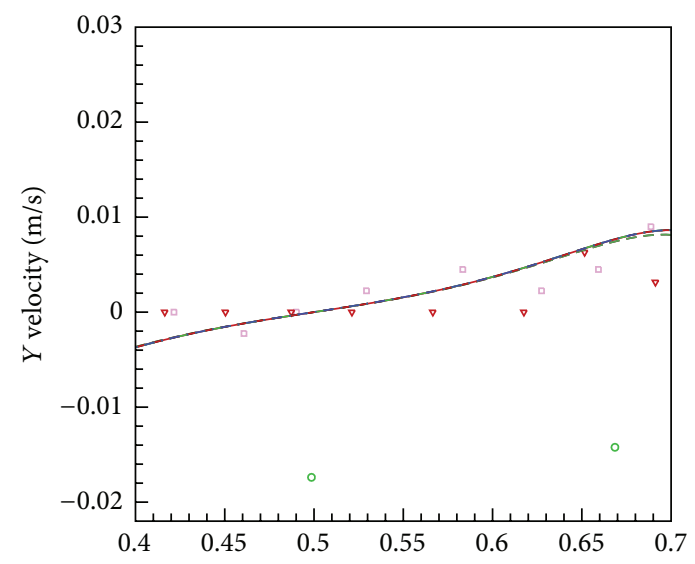

(d) $0.40 \leq X \leq 0.70$

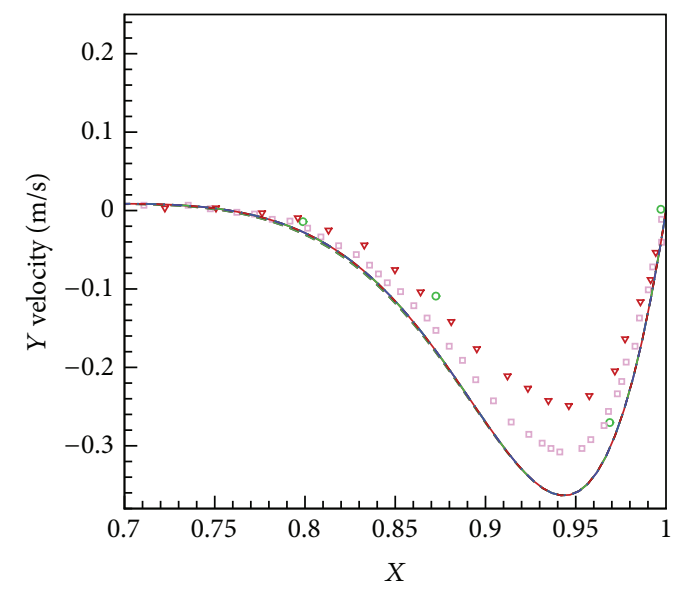

- Krane and Jessee [32], _ - - 2nd order/SIMPLEC experimental work $\quad$....... Power law/SIMPLE

- Bakhshan and Emrani [33], — Power law/SIMPLEC numerical work $\ldots$ QUICK/SIMPLE

$\checkmark$ LBM .... QUICK/SIMPLEC

- - 1 st order/SIMPLE

- - 1 st order/SIMPLEC 2nd order/SIMPLE

(e) $0.70 \leq X \leq 1.00$

FIGURE 3: Vertical velocity profile at midheight. 


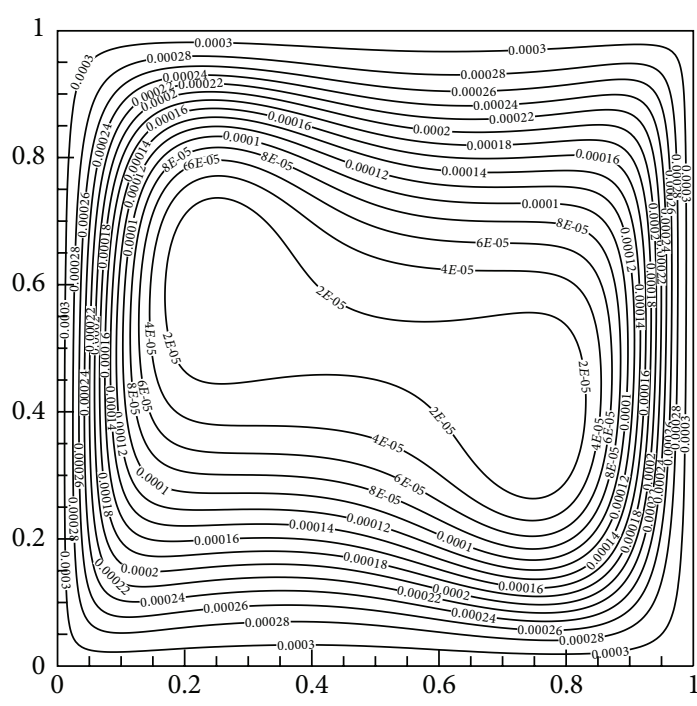

(a) 1st order upwind/SIMPLE

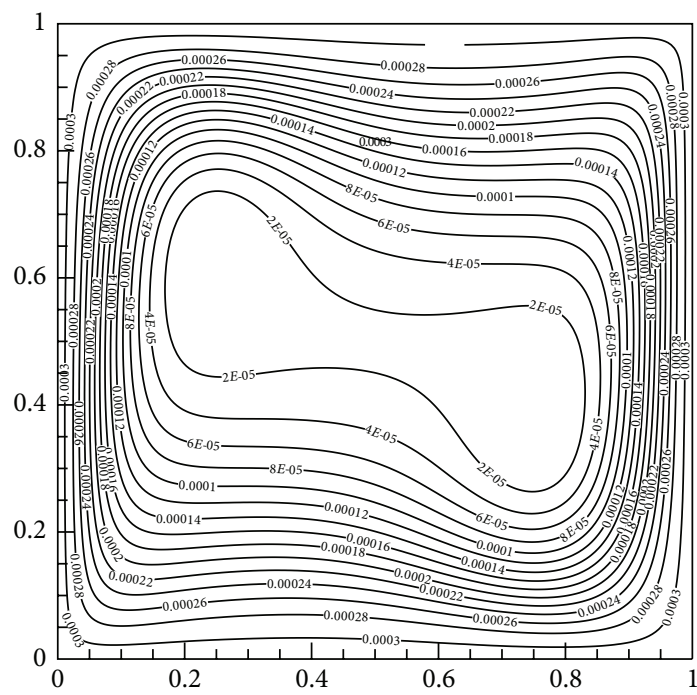

(c) 1st order upwind/SIMPLEC

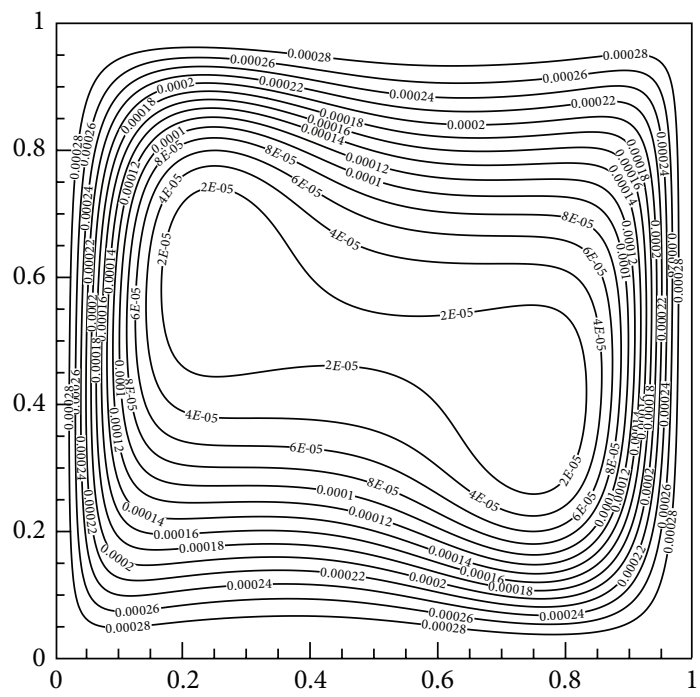

(e) Power law/SIMPLE

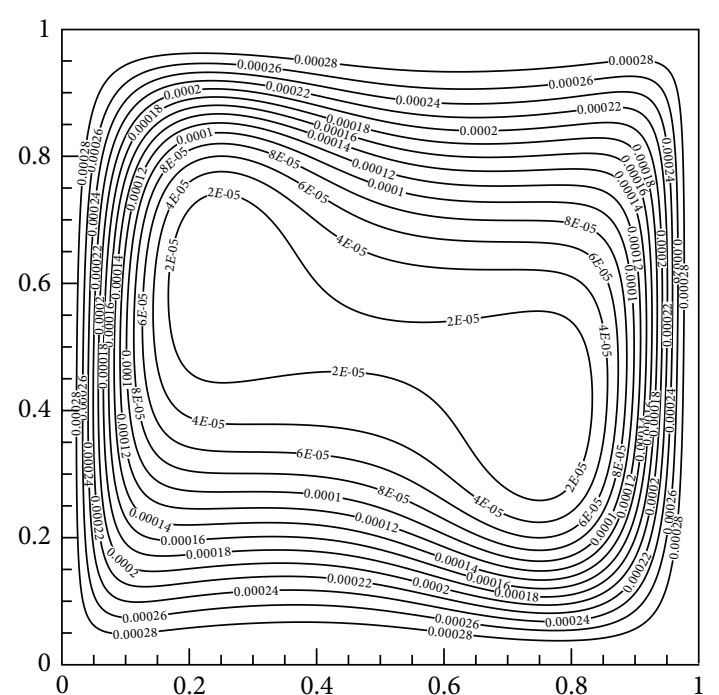

(b) 2nd order upwind/SIMPLE

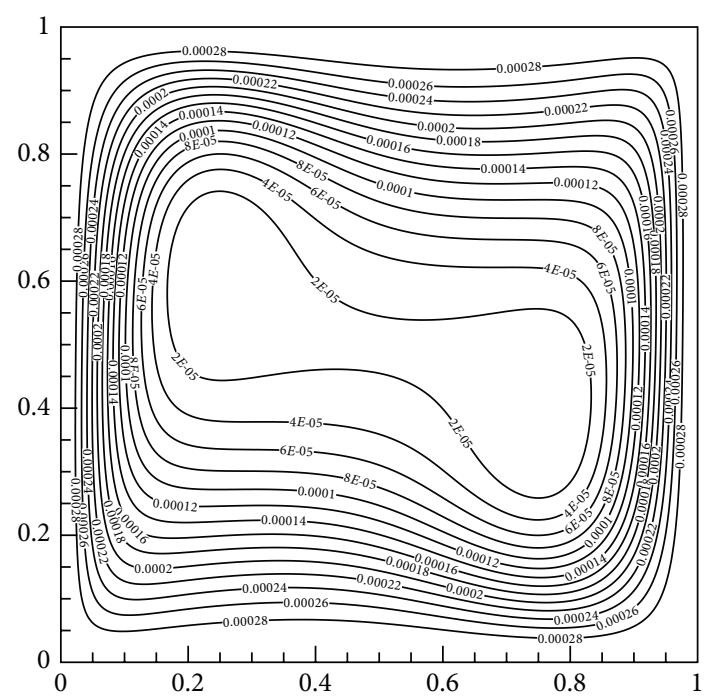

(d) 2nd order upwind/SIMPLEC

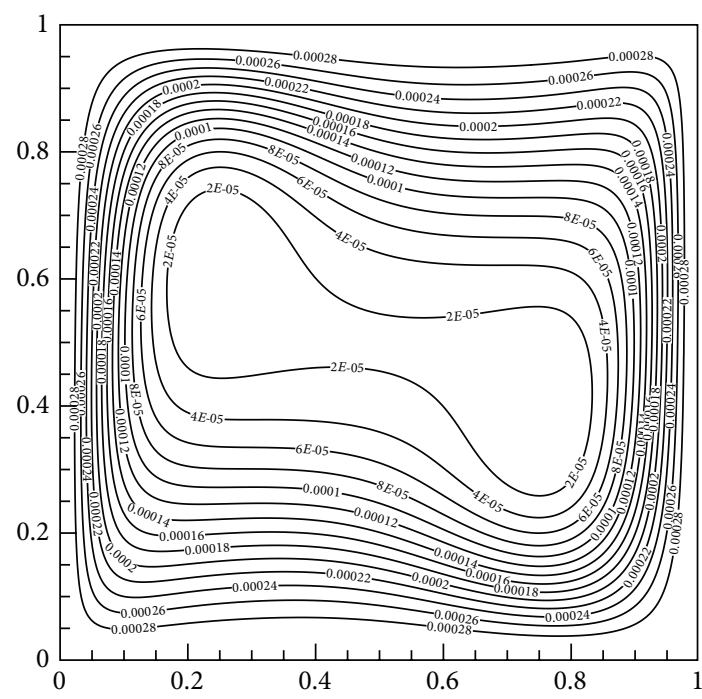

(f) QUICK/SIMPLE

Figure 4: Continued. 


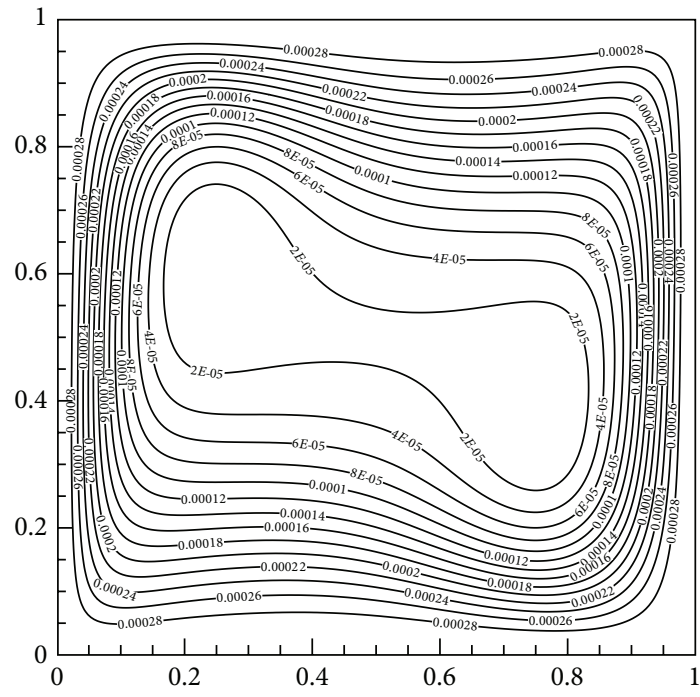

(g) Power law/SIMPLEC

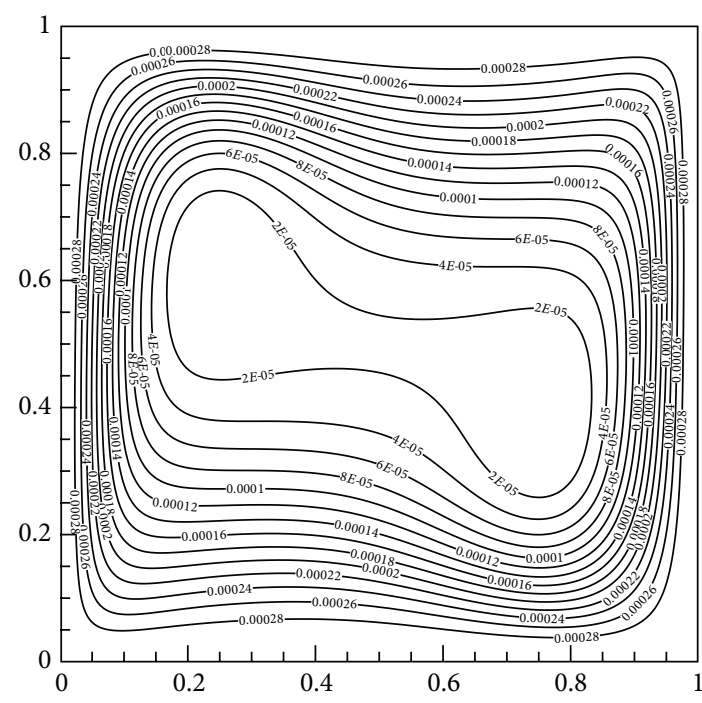

(h) QUICK/SIMPLEC

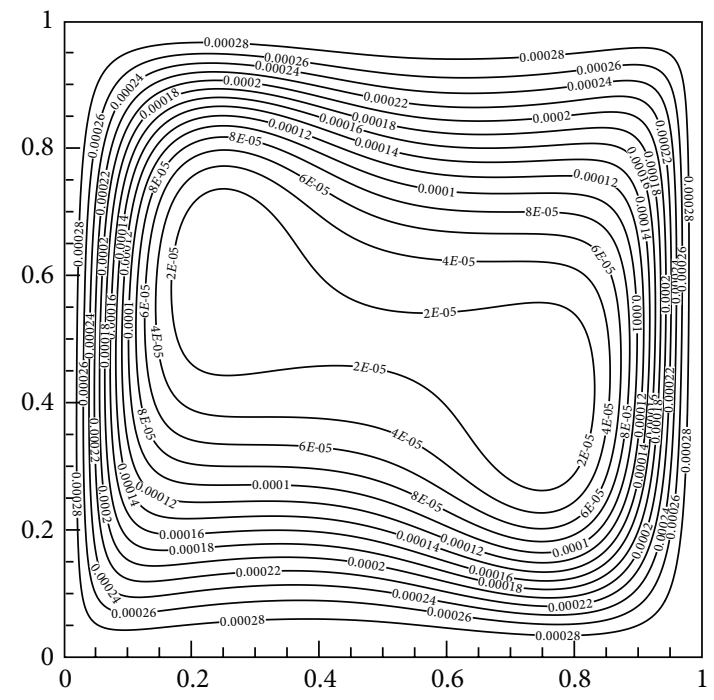

(i) LBM

FIGURE 4: Streamlines contours.

TABLE 4: Comparison of the average Nusselt number along the hot wall with those in the literature.

\begin{tabular}{|c|c|c|c|c|}
\hline & $\mathrm{Ra}=10^{3}$ & $\mathrm{Ra}=10^{4}$ & $\mathrm{Ra}=10^{5}$ & $\mathrm{Ra}=10^{6}$ \\
\hline Khanafer et al. [34], FVM & 1.118 & 2.245 & 4.522 & 8.826 \\
\hline Barakos et al. [39], FVM & 1.114 & 2.245 & 4.510 & 8.806 \\
\hline Markatos and Pericleous [40], FDM & 1.108 & 2.201 & 4.430 & 8.754 \\
\hline de Vahl Davis [41], FDM & 1.118 & 2.243 & 4.519 & 8.799 \\
\hline Fusegi et al. [42], 3-D FDM & 1.105 & 2.302 & 4.646 & 9.012 \\
\hline 1st upwind/SIMPLE & 1.115 & 2.233 & 4.508 & 8.756 \\
\hline 1st upwind/SIMPLEC & 1.120 & 2.242 & 4.516 & 8.795 \\
\hline 2nd upwind/SIMPLE & 1.116 & 2.236 & 4.465 & 8.761 \\
\hline 2nd upwind/SIMPLEC & 1.119 & 2.240 & 4.489 & 8.799 \\
\hline Power law/SIMPLE & 1.115 & 2.235 & 4.465 & 8.754 \\
\hline Power law/SIMPLEC & 1.116 & 2.238 & 4.475 & 8.765 \\
\hline QUICK/SIMPLE & 1.119 & 2.242 & 4.502 & 8.786 \\
\hline QUICK/SIMPLEC & 1.113 & 2.230 & 4.479 & 8.757 \\
\hline LBM & 1.108 & 2.210 & 4.456 & 8.756 \\
\hline
\end{tabular}




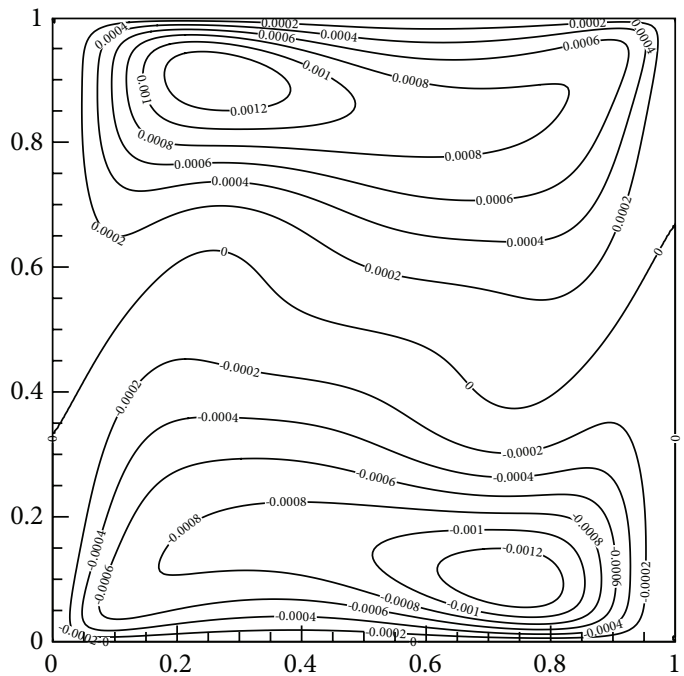

(a) 1st order upwind/SIMPLE

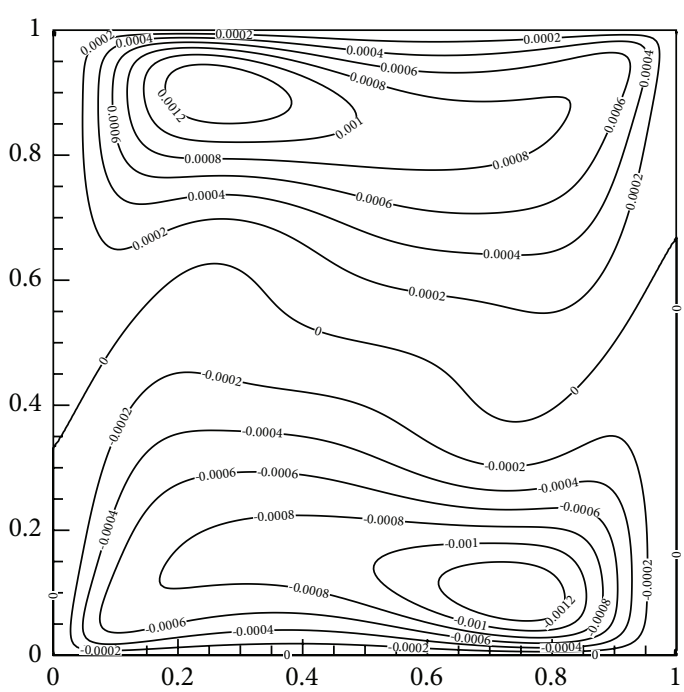

(c) 1st order upwind/SIMPLEC

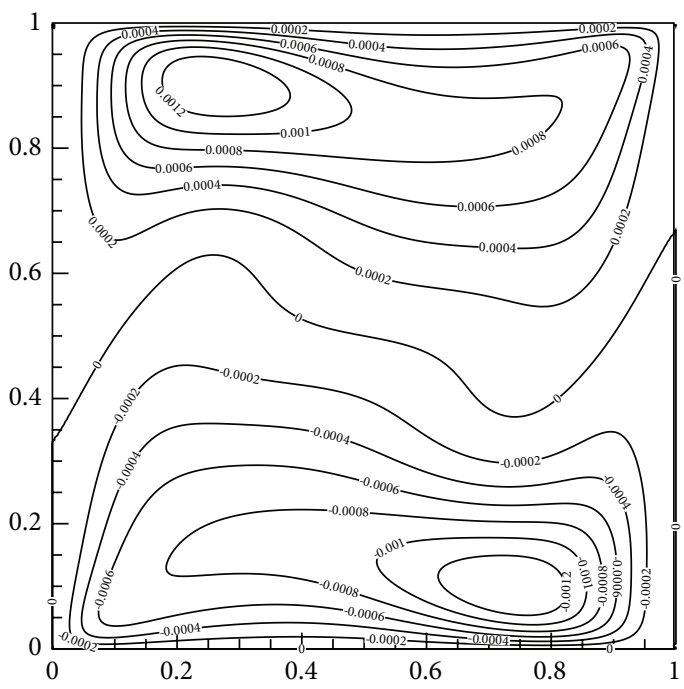

(e) Power law/SIMPLE

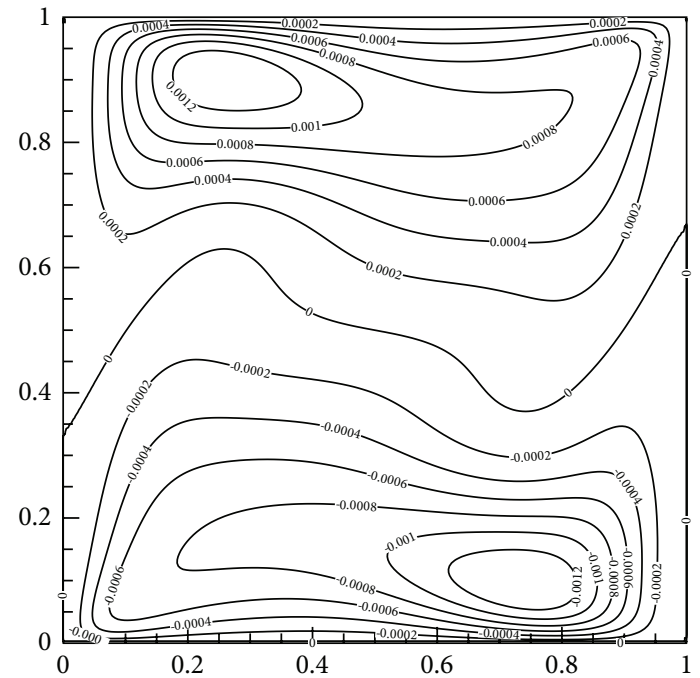

(b) 2nd order upwind/SIMPLE

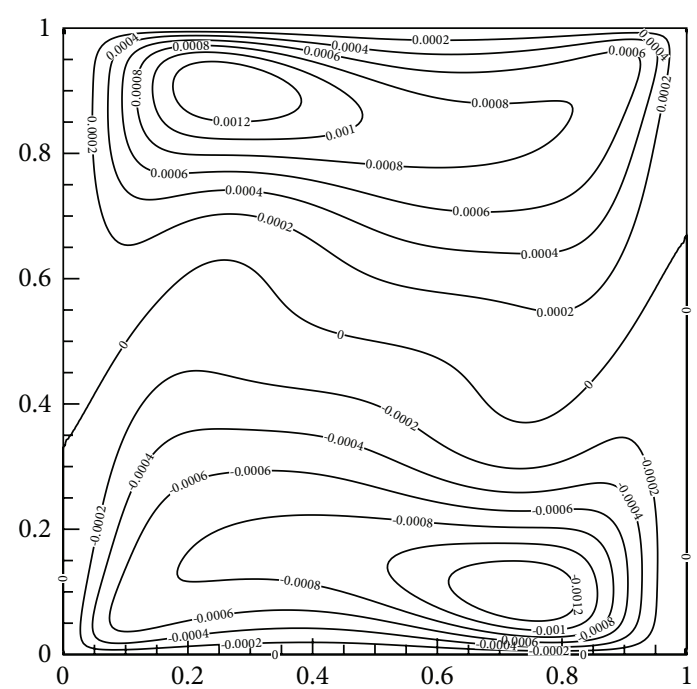

(d) 2nd order upwind/SIMPLEC

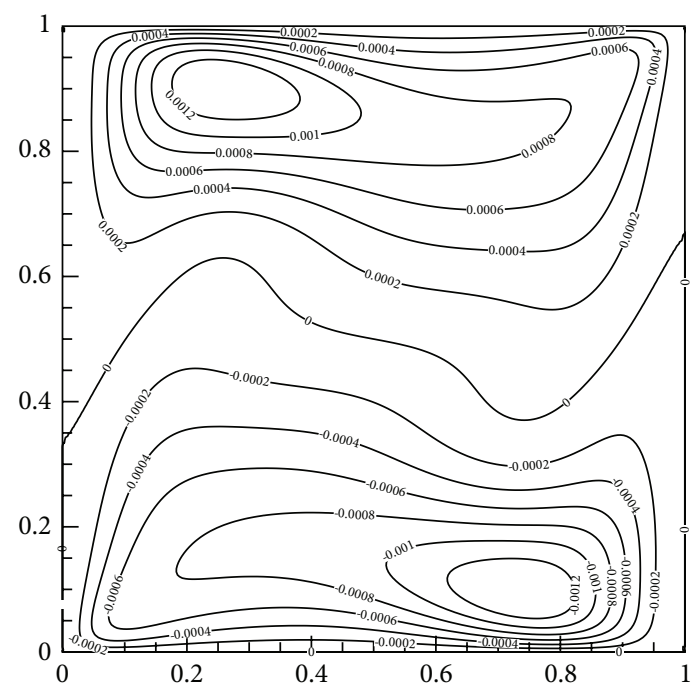

(f) QUICK/SIMPLE

Figure 5: Continued. 


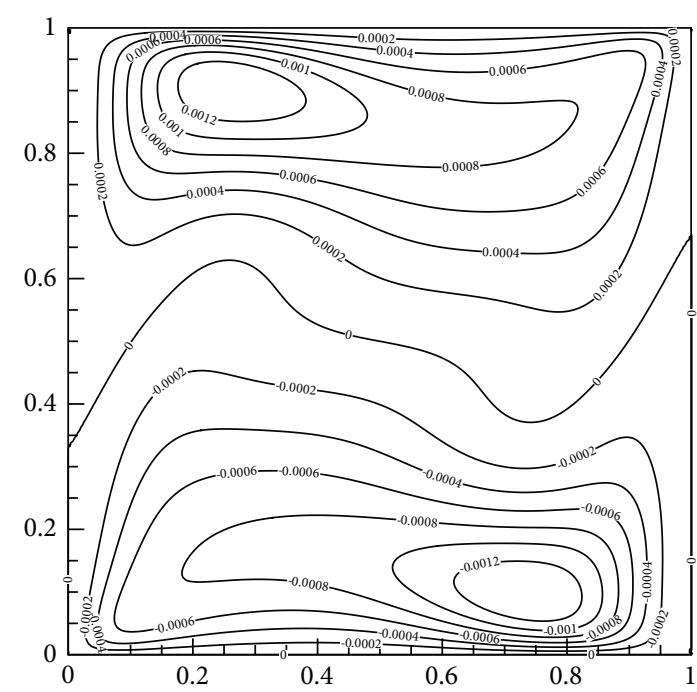

(g) Power law/SIMPLEC

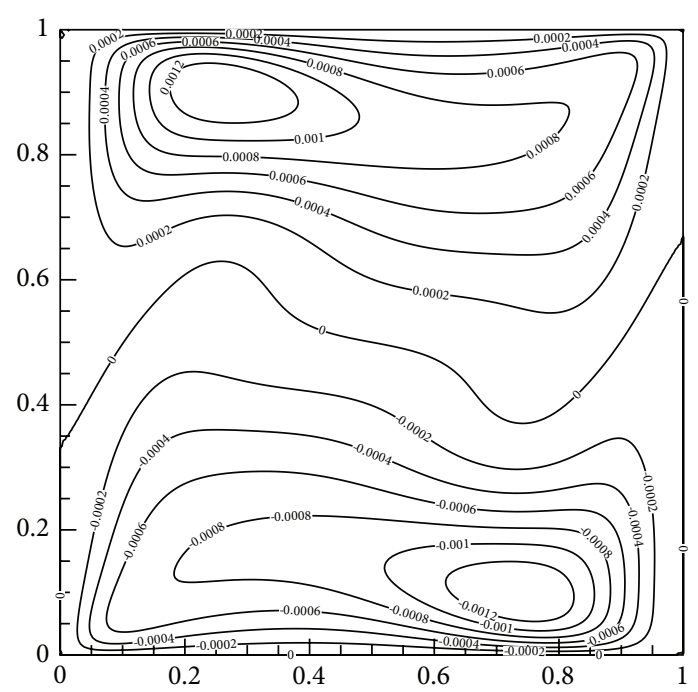

(h) QUICK/SIMPLEC

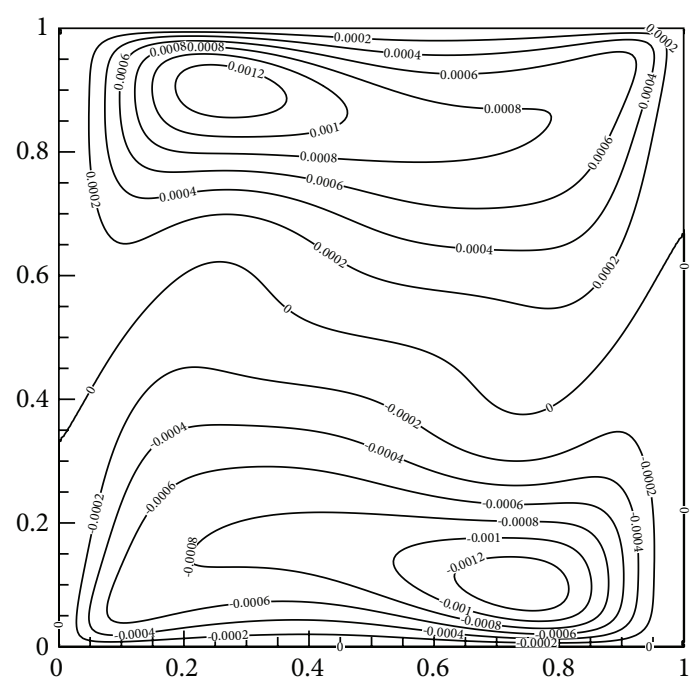

(i) LBM

FIgURE 5: $X$-velocity contours.

TABLE 5: Number of iterations and solving time for different discretization method.

\begin{tabular}{lcccc}
\hline Type of method & Case number & $\begin{array}{c}\text { Discretization method/pressure-velocity } \\
\text { linking approach }\end{array}$ & Number of iterations & Solving time (s) \\
\hline & 1 & 1st upwind/SIMPLE & 1571 & 482 \\
& 2 & 1st upwind/SIMPLEC & 1572 & 486 \\
\multirow{3}{*}{ Finite volume method } & 3 & 2nd upwind/SIMPLE & 1597 & 502 \\
& 4 & 2nd upwind/SIMPLEC & 1598 & 509 \\
& 5 & Power law/SIMPLE & 1520 & 469 \\
& 6 & Power law/SIMPLEC & 1521 & 474 \\
\hline Lattice Boltzmann method & 7 & QUICK/SIMPLE & 1598 & 510 \\
\hline
\end{tabular}




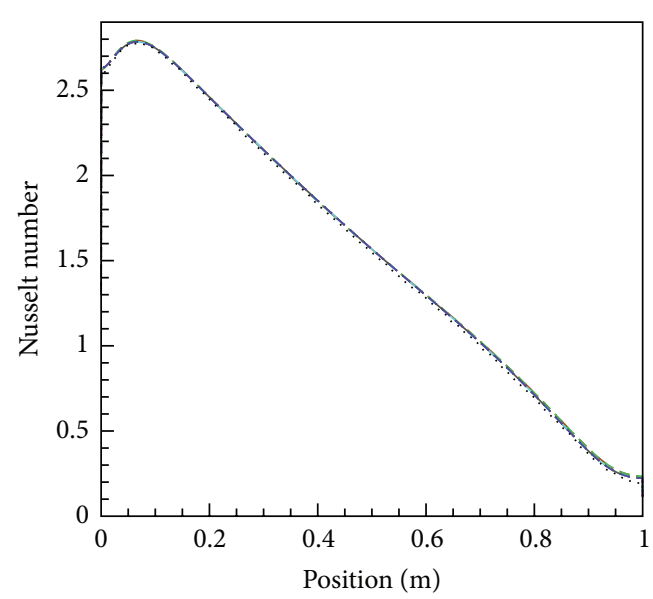

(a) $0.00 \leq Y \leq 1.00$

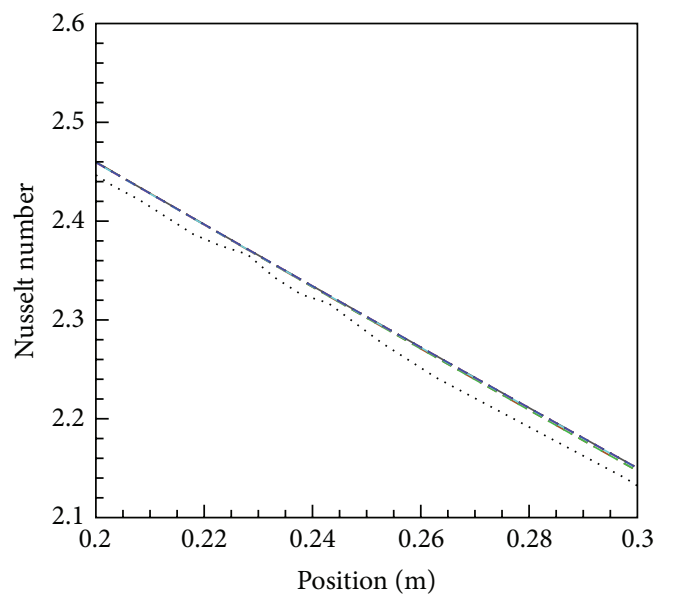

(c) $0.20 \leq Y \leq 0.30$

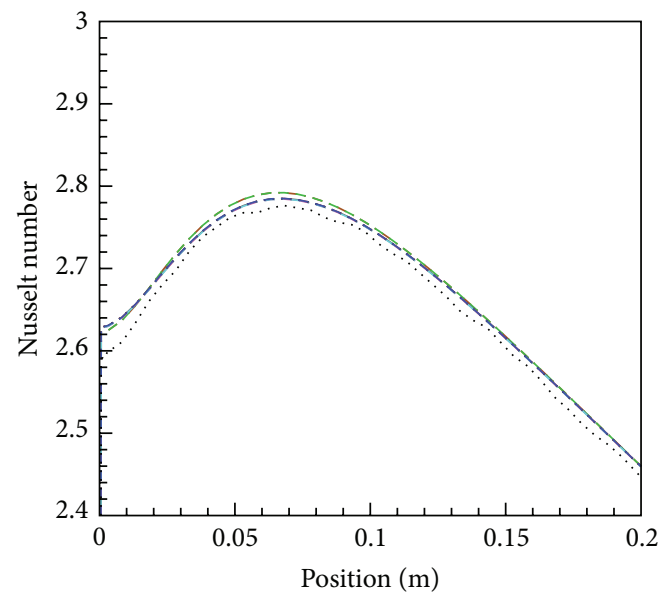

(b) $0.00 \leq Y \leq 0.20$

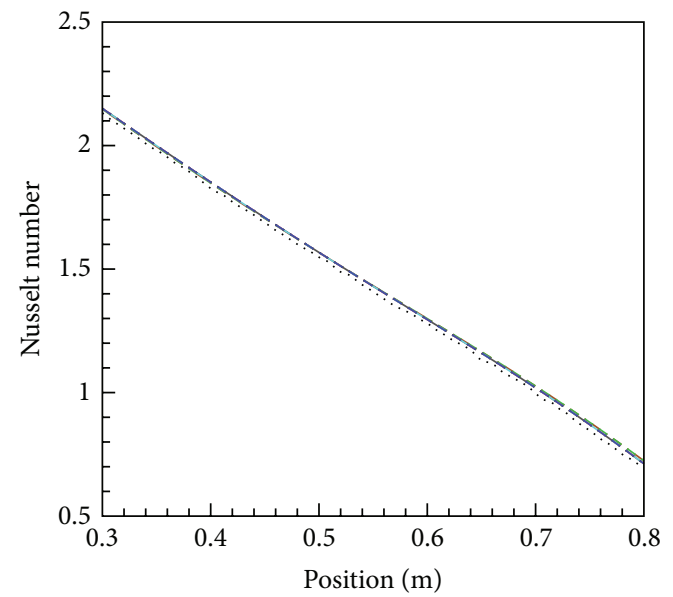

(d) $0.30 \leq Y \leq 0.80$

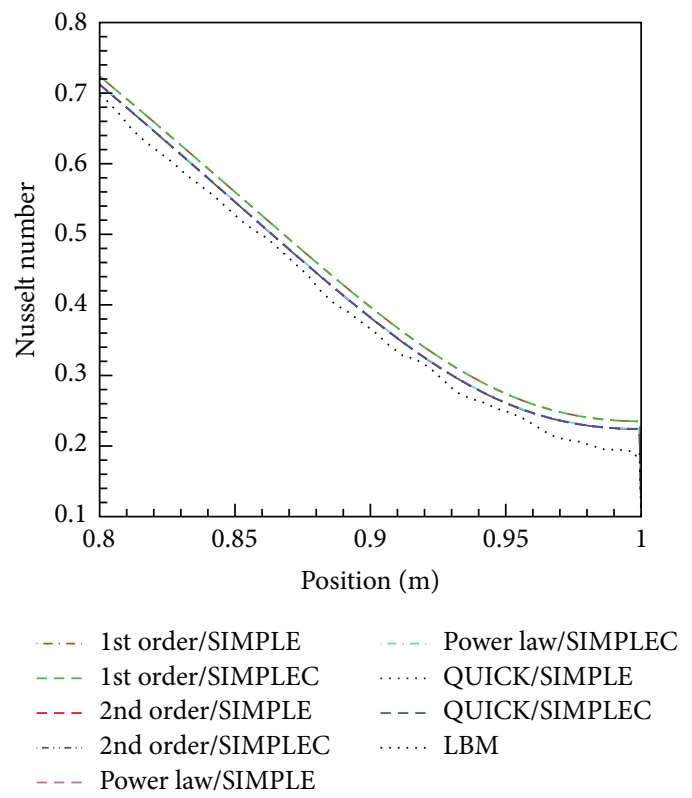

(e) $0.80 \leq Y \leq 1.00$

FIGURE 6: Nusselt number profile at hot wall. 
the studied discretization schemes, especially in the northwest and southeast sides of the enclosure. Regarding the pressure/velocity coupling approaches, the maximum stream function values for the SIMPLE and SIMPLEC approaches are 0.0003 and 0.0003066 , respectively, translating into $2.2 \%$ difference while the CPU usage time difference is only $4 \mathrm{~s}$. For LBM, the value of stream function is 0.000278 .

For the velocity contours in the $X$ direction Figure 5 shows that the $U$-velocity contours have cross-diagonal similarity towards the $Y=X$ axis. Thus, all the methods analyzed present comparable results with no obvious difference.

Figure 6 demonstrates the local Nusselt number distributions along the left hot wall. For all discretization schemes, the Nusselt number is high near the bottom of the left wall (because of extreme temperature variations) and declines towards the top of the wall. The comparison between different solvers reveals that the 1st order upwind scheme predicts the maximum Nusselt number while LBM leads to the lowest one with some fluctuations along the hot wall. Interestingly, LBM uses about $40 \%$ more grids in that region compared to FVM ones.

\section{Conclusions}

Numerical tests using the finite volume and lattice Boltzmann methods with various discretization schemes and pressurevelocity linking algorithms were conducted to obtain the optimum discretization/linking approaches to address the internal convective heat transfer problems. The flow and temperature fields, as well as number of iterations and solving time, were evaluated.

The significant observations made in this study are summarized as follows.

(1) The finite volume method results are more accurate compared to those of LBM, especially at the corners.

(2) LBM needs a 4-5-fold CPU usage time and 8-9 times more iterations compared to the finite volume method to solve the problem considered here.

(3) Among the studied discretization/pressure-velocity linking algorithms, the 1st order upwind/SIMPLEC provides the most precise results against experimental benchmark data, especially in the boundary layers.

(4) The numbers of iterations for all FVM discretization/ pressure-velocity linking methods are nearly equal.

(5) The higher-order accurate schemes are more time consuming.

One, however, notes that the above observations are valid within the limits of the parameters and problem considered in this study and could not be generalized to other cases without further investigations.

\section{Nomenclature}

$\begin{array}{ll}x, y: & \text { Cartesian coordinates }(\mathrm{m}) \\ f: & \text { Density-momentum distribution function } \\ H, L: & \text { Enclosure height and width }(\mathrm{m}) \\ \mathrm{Gr}: & \text { Grashof number }\left(g \beta T L^{3} v^{-2}\right) \\ \vec{g}: & \text { Gravitational acceleration }\left(\mathrm{m} \mathrm{s}^{2}\right) \\ Z: & \text { Heat dissipation } \\ g: & \text { Internal energy distribution function } \\ c: & \text { Microscopic velocity vector } \\ \mathrm{Pr}: & \text { Prandtl number }\left(v \alpha^{-1}\right) \\ P: & \text { Pressure }\left(\mathrm{N} \mathrm{m}{ }^{2}\right) \\ \mathrm{Ra}: & \text { Rayleigh number }(\mathrm{Gr} \text { Pr) } \\ C_{p}: & \text { Specific heat capacity }\left(\mathrm{J} \mathrm{kg}^{1} \mathrm{~K}^{1}\right) \\ T, t: & \text { Temperature, time }(\mathrm{K}),(\mathrm{S}) \\ k: & \text { Thermal conductivity }\left(\mathrm{W} \mathrm{m}^{-1} \mathrm{~K}^{-1}\right) \\ u=(u, v): & \text { Velocities vector and its components in } X \\ & \text { and } Y \text { directions }\left(\mathrm{m} \mathrm{s}^{1}\right) .\end{array}$

Greek Symbols

$\mu$ : Dynamic viscosity $(\mathrm{PaS})$

$\rho:$ Density $\left(\mathrm{kg} \mathrm{m}^{3}\right)$

$\tau_{g}$ : Internal energy relaxation times

$v$ : Kinematics viscosity $\left(\mathrm{m}^{2} \mathrm{~s}^{1}\right)$

$\tau_{f}$ : Momentum relaxation times

$\beta$ : Thermal expansion coefficient $\left(\mathrm{K}^{1}\right)$

$\alpha$ : Thermal diffusivity, $x-y$ direction components $\left(\mathrm{m}^{2} \mathrm{~s}^{1}\right)$.

Subscripts

$c$ : Cold wall

$e:$ Equilibrium distribution function

$h$ : Hot wall

$i$ : Lattice velocity direction.

\section{Conflict of Interests}

The authors declare that there is no conflict of interests regarding the publication of this paper.

\section{Acknowledgments}

The authors gratefully acknowledge the High Impact Research Grant UM.C/HIR/MOHE/ENG/23, UMRG Grant RP012C-13AET and the University of Malaya, Malaysia, for support in conducting this research work.

\section{References}

[1] F. S. Mirhashemi and S. H. Hashemabadi, "Experimental and CFD study of wall effects on orderly stacked cylindrical particles heat transfer in a tube channel," International Communications in Heat and Mass Transfer, vol. 39, no. 3, pp. 449-455, 2012.

[2] C. Bellecci, P. Gaudio, I. Lupelli et al., "Loss of vacuum accident (LOVA): comparison of computational fluid dynamics (CFD) flow velocities against experimental data for the model 
validation," Fusion Engineering and Design, vol. 86, no. 4-5, pp. 330-340, 2011.

[3] M. Selmi, M. J. Al-Khawaja, and A. Marafia, "Validation of CFD simulation for flat plate solar energy collector," Renewable Energy, vol. 33, no. 3, pp. 383-387, 2008.

[4] A. G. Dixon, G. Walls, H. Stanness, M. Nijemeisland, and E. H. Stitt, "Experimental validation of high Reynolds number CFD simulations of heat transfer in a pilot-scale fixed bed tube," Chemical Engineering Journal, vol. 200, pp. 344-356, 2012.

[5] Z. Zhang and X. Zhang, "Direct simulation of low-re flow around a square cylinder by numerical manifold method for Navier-Stokes equations," Journal of Applied Mathematics, vol. 2012, Article ID 465972, 14 pages, 2012.

[6] J. Nordström, J. Gong, E. van der Weide, and M. Svärd, "A stable and conservative high order multi-block method for the compressible Navier-Stokes equations," Journal of Computational Physics, vol. 228, no. 24, pp. 9020-9035, 2009.

[7] Z. Chen and L. Zhang, "A stabilized mixed finite element method for single-phase compressible flow," Journal of Applied Mathematics, vol. 2011, Article ID 129724, 2011.

[8] S. Boivin, F. Cayré, and J. Hérard, "A finite volume method to solve the Navier-Stokes equations for incompressible flows on unstructured meshes," International Journal of Thermal Sciences, vol. 39, no. 8, pp. 806-821, 2000.

[9] X. Liu, H. Liu, and Y. Liu, "Simulation of magnetorheological fluids based on Lattice Boltzmann method with double meshes," Journal of Applied Mathematics, vol. 2012, Article ID 567208, 16 pages, 2012.

[10] A. A. Mohamad, Lattice Boltzmann Method: Fundamentals and Engineering Applications with Computer Codes, Springer, 2011.

[11] Y. Shi, T. S. Zhao, and Z. L. Guo, "Lattice Boltzmann method for incompressible flows with large pressure gradients," Physical Review E, vol. 73, no. 2, Article ID 026704, 2006.

[12] A. Karimipour, A. H. Nezhad, A. D’Orazio, and E. Shirani, “The effects of inclination angle and prandtl number on the mixed convection in the inclined lid driven cavity using lattice boltzmann method," Journal of Theoretical and Applied Mechanics, vol. 51, no. 2, pp. 447-462, 2013.

[13] A. Rouboa and E. Monteiro, "Heat transfer in multi-block grid during solidification: performance of finite differences and finite volume methods," Journal of Materials Processing Technology, vol. 204, no. 1-3, pp. 451-458, 2008.

[14] A. Karimipour, M. Afrand, M. Akbari, and M. R. Safaei, "Simulation of fluid flow and heat transfer in the inclined enclosure," in Proceedings of the World Academy of Science, Engineering and Technology, World Academy of Science, Engineering and Technology, 2012.

[15] F. Garoosi, G. Bagheri, and F. Talebi, "Numerical simulation of natural convection of nanofluids in a square cavity with several pairs of heaters and coolers (HACs) inside," International Journal of Heat and Mass Transfer, vol. 67, pp. 362-376, 2013.

[16] H. Bararnia, K. Hooman, and D. D. Ganji, "Natural convection in a nanofluids-filled portioned cavity: the lattice-boltzmann method," Numerical Heat Transfer A, vol. 59, no. 6, pp. 487-502, 2011.

[17] G. Imani, M. Maerefat, and K. Hooman, "Lattice Boltzmann simulation of conjugate heat transfer from multiple heated obstacles mounted in a walled parallel plate channel," Numerical Heat Transfer A, vol. 62, no. 10, pp. 798-821, 2012.

[18] Z. Tian, C. Zou, H. J. Liu, Z. H. Liu, Z. L. Guo, and C. G. Zheng, "Thermal lattice boltzmann model with viscous heat dissipation in the incompressible limit," International Journal of Modern Physics C, vol. 17, no. 8, pp. 1131-1139, 2006.

[19] Q. Zou and X. He, "On pressure and velocity boundary conditions for the lattice Boltzmann BGK model," Physics of Fluids, vol. 9, no. 6, pp. 1591-1596, 1997.

[20] S. V. Patankar, Numerical Heat Transfer and Fluid Flow, Taylor \& Francis, 1980.

[21] M. R. Safaei, B. Rahmanian, and M. Goodarzi, "Numerical study of laminar mixed convection heat transfer of power-law non-Newtonian fluids in square enclosures by finite volume method," International Journal of Physical Sciences, vol. 6, no. 33, pp. 7456-7470, 2011.

[22] M. R. Safaei, H. R. Goshayeshi, B. S. Razavi, and M. Goodarzi, "Numerical investigation of laminar and turbulent mixed convection in a shallow water-filled enclosure by various turbulence methods," Scientific Research and Essays, vol. 6, no. 22, pp. 48264838, 2011.

[23] M. Goodarzi, M. R. Safaei, K. Vafai et al., "Investigation of nanofluid mixed convection in a shallow cavity using a two-phase mixture model," International Journal of Thermal Sciences, vol. 75, pp. 204-220, 2014.

[24] S. S. Mousavi and K. Hooman, "Heat and fluid flow in entrance region of a channel with staggered baffles," Energy Conversion and Management, vol. 47, no. 15-16, pp. 2011-2019, 2006.

[25] W. Q. Tao, Y. L. He, Z. Y. Li, and Z. G. Qu, “Some recent advances in finite volume approach and their applications in the study of heat transfer enhancement," International Journal of Thermal Sciences, vol. 44, no. 7, pp. 623-643, 2005.

[26] P. Forooghi and K. Hooman, "Numerical study of turbulent convection in inclined pipes with significant buoyancy influence," International Journal of Heat and Mass Transfer, vol. 61, no. 1, pp. 310-322, 2013.

[27] M. R. Safaei, M. Goodarzi, and M. Mohammadi, "Numerical modeling of turbulence mixed convection heat transfer in air filled enclosures by finite volume method," International Journal of Multiphysics, vol. 5, no. 4, pp. 307-324, 2011.

[28] H. Goshayeshi, M. R. Safaei, and Y. Maghmoumi, "Numerical simulation of unsteady turbulent and laminar mixed convection in rectangular enclosure with hot upper moving wall by finite volume method," in Proceedings of the 6th International Chemical Engineering Congress and Exhibition (IChEC '09), Kish Island, Iran, 2009.

[29] N. Lancial, F. Beaubert, S. Harmand, and G. Rolland, "Effects of a turbulent wall jet on heat transfer over a non-confined backward-facing step," International Journal of Heat and Fluid Flow, vol. 44, pp. 336-347, 2013.

[30] S. Hou, Q. Zou, S. Chen, G. Doolen, and A. C. Cogley, "Simulation of cavity flow by the lattice Boltzmann method," Journal of Computational Physics, vol. 118, no. 2, pp. 329-347, 1995.

[31] A. D’Orazio, C. Arrighetti, and S. Succi, Kinetic Scheme for Fluid Flows with Heat Transfer, University of Rome "La Sapienza", Roma, Italy, 2003.

[32] R. Krane and J. Jessee, "Some detailed field measurements for a natural convection flow in a vertical square enclosure," in Proceedings of the 1st ASME-JSME Thermal Engineering Joint Conference, pp. 323-329, 1983.

[33] Y. Bakhshan and S. H. Emrani, "Investigating the behavior of nanofluids in a rectangular enclosure in order to enhance the heat transfer coefficient," Journal of Basic and Applied Scientific Research and Essays, vol. 3, no. 1, pp. 976-986, 2013. 
[34] K. Khanafer, K. Vafai, and M. Lightstone, "Buoyancy-driven heat transfer enhancement in a two-dimensional enclosure utilizing nanofluids," International Journal of Heat and Mass Transfer, vol. 46, no. 19, pp. 3639-3653, 2003.

[35] H. F. Oztop and E. Abu-Nada, "Numerical study of natural convection in partially heated rectangular enclosures filled with nanofluids," International Journal of Heat and Fluid Flow, vol. 29, no. 5, pp. 1326-1336, 2008.

[36] J. M. Buick and C. A. Created, "Gravity in a lattice Boltzmann model," Physical Review E, vol. 61, no. 5 A, pp. 5307-5320, 2000.

[37] X. He and L. Luo, "Lattice Boltzmann model for the incompressible Navier-Stokes equation," Journal of Statistical Physics, vol. 88, no. 3-4, pp. 927-944, 1997.

[38] W. Tao, Recent Advances in Computational Heat Transfer, Science Press, Beijing, China, 2000.

[39] G. Barakos, E. Mitsoulis, and D. Assimacopoulos, "Natural convection flow in a square cavity revisited: laminar and turbulent models with wall functions," International Journal for Numerical Methods in Fluids, vol. 18, no. 7, pp. 695-719, 1994.

[40] N. C. Markatos and K. A. Pericleous, "Laminar and turbulent natural convection in an enclosed cavity," International Journal of Heat and Mass Transfer, vol. 27, no. 5, pp. 755-772, 1984.

[41] G. de Vahl Davis, "Natural convection of air in a square cavity: a bench mark numerical solution," International Journal for Numerical Methods in Fluids, vol. 3, no. 3, pp. 249-264, 1983.

[42] T. Fusegi, J. M. Hyun, K. Kuwahara, and B. Farouk, "A numerical study of three-dimensional natural convection in a differentially heated cubical enclosure," International Journal of Heat and Mass Transfer, vol. 34, no. 6, pp. 1543-1557, 1991.

[43] A. Karimipour, A. H. Nezhad, A. D’Orazio, and E. Shirani, "Investigation of the gravity effects on the mixed convection heat transfer in a microchannel using lattice Boltzmann method," International Journal of Thermal Sciences, vol. 54, pp. 142-152, 2012. 


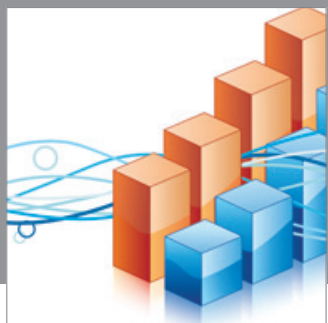

Advances in

Operations Research

mansans

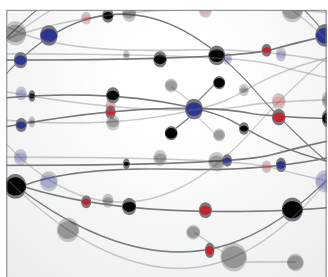

The Scientific World Journal
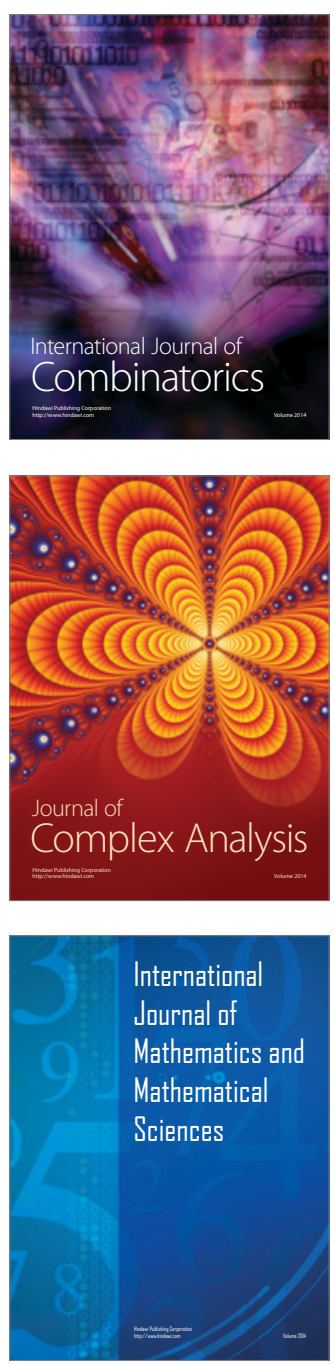
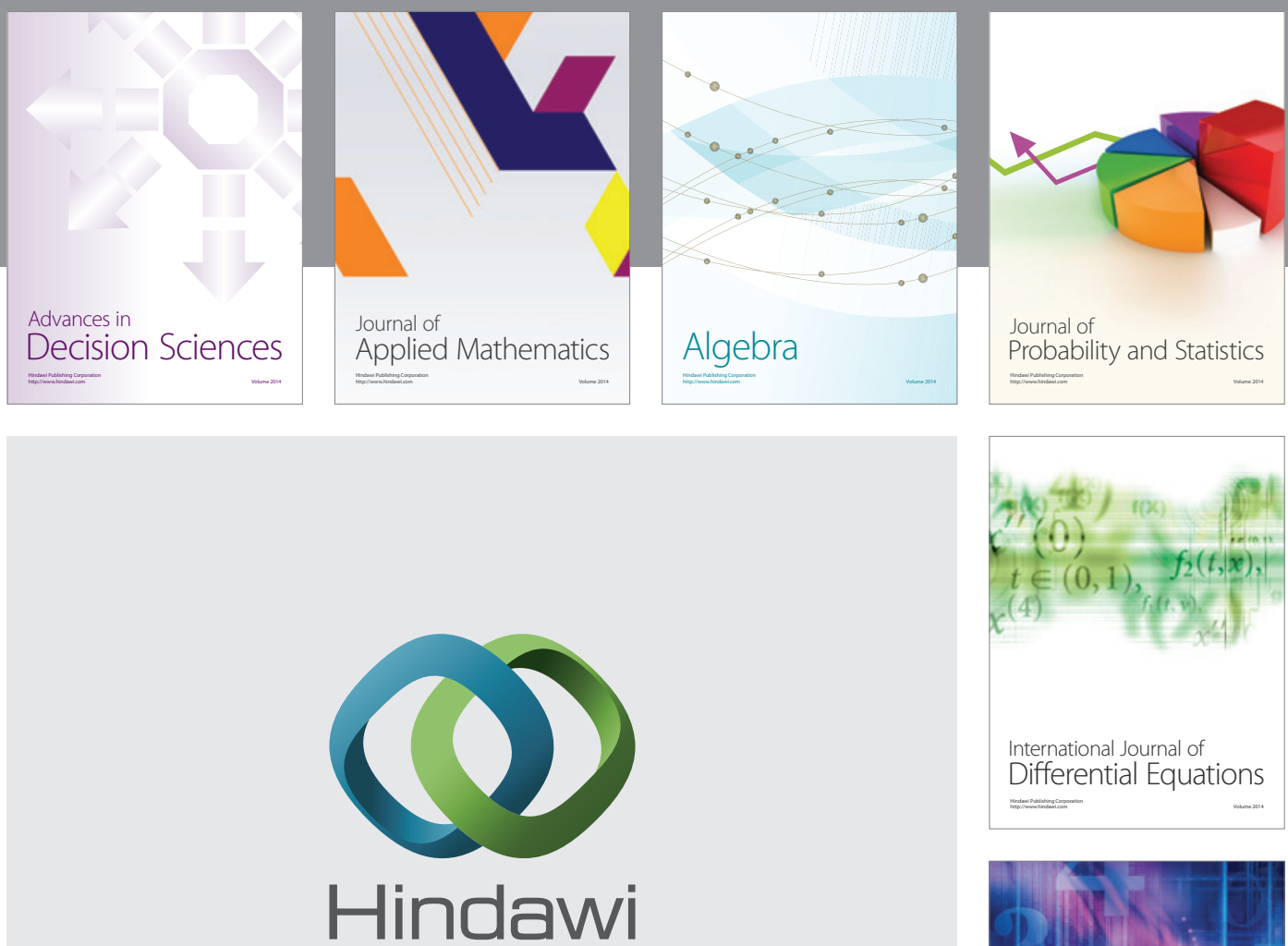

Submit your manuscripts at http://www.hindawi.com
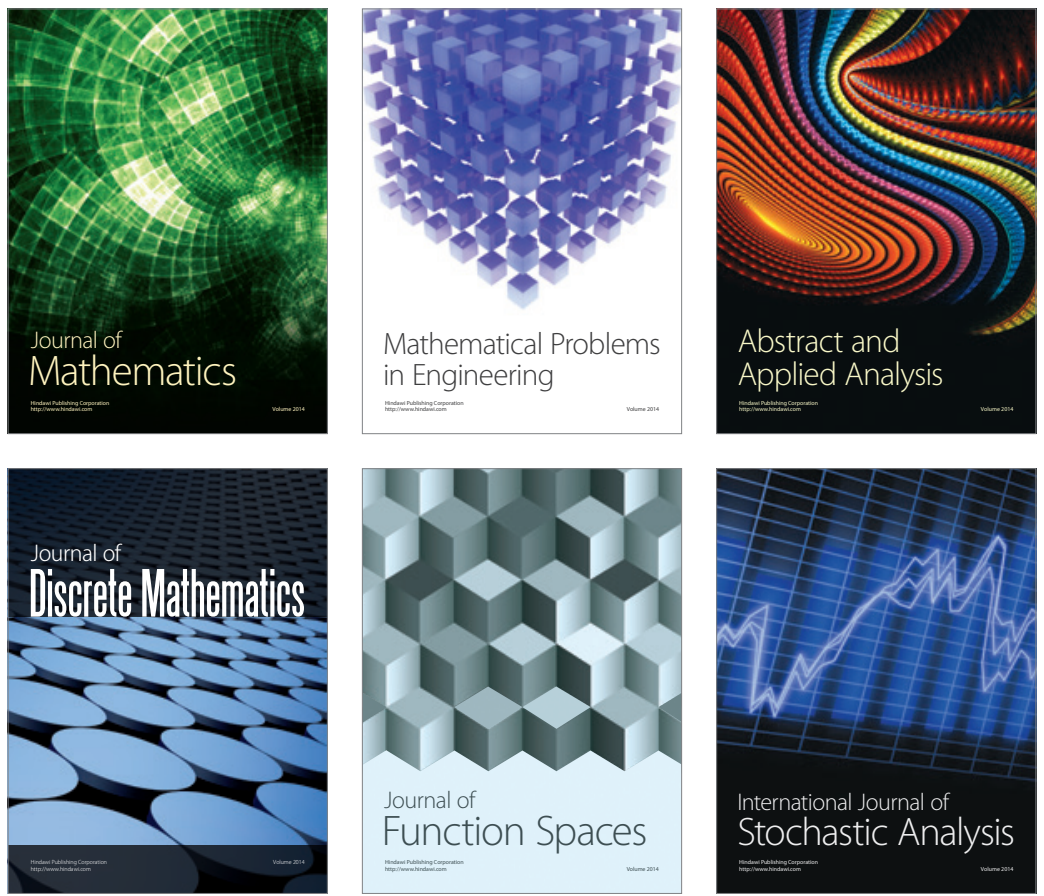

Journal of

Function Spaces

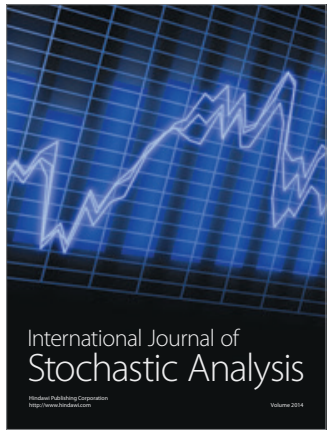

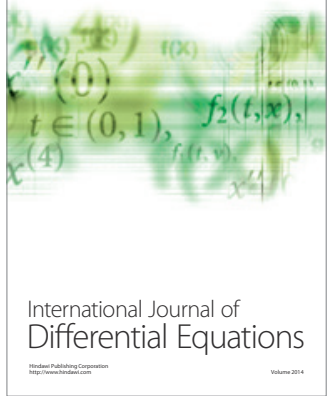
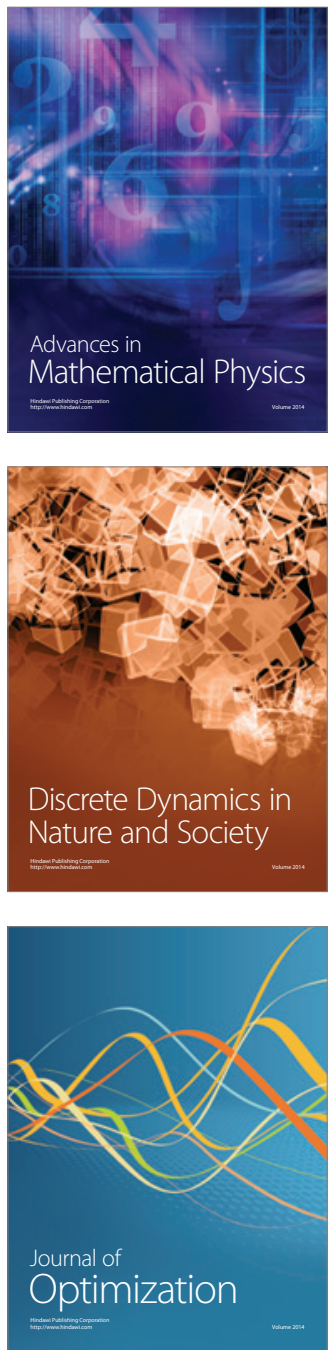